$$
\text { RODRIGO OTÁVIO CORREIA DA SILVA }
$$

\title{
Efeito da adição de antioxidantes enzimáticos na criopreservação do sêmen caprino
}




\section{Efeito da adição de antioxidantes enzimáticos na criopreservação do sêmen caprino}

Dissertação apresentada ao Programa de PósGraduação em Reprodução Animal da

Faculdade de Medicina Veterinária e Zootecnia da Universidade de São Paulo para obtenção do título de Mestre em Ciências

Departamento:

Reprodução Animal

Área de concentração:

Reprodução Animal

Orientador:

Prof.(a) Dra. Valquiria Hyppolito Barnabe

São Paulo 
Autorizo a reprodução parcial ou total desta obra, para fins acadêmicos, desde que citada a fonte.

DADOS INTERNACIONAIS DE CATALOGAÇÃO-NA-PUBLICAÇÃO

(Biblioteca Virginie Buff D’Ápice da Faculdade de Medicina Veterinária e Zootecnia da Universidade de São Paulo)

Silva, Rodrigo Otávio Correia da

FMVZ

Efeito da adição de antioxidantes enzimáticos na criopreservação do sêmen caprino / Rodrigo Otávio Correia da Silva. -- 2011.

83 f. : il.

Dissertação (Mestrado) - Universidade de São Paulo. Faculdade de Medicina Veterinária e Zootecnia. Departamento de Reprodução Animal, São Paulo, 2011.

Programa de Pós-Graduação: Reprodução Animal.

Área de concentração: Reprodução Animal.

Orientador: Profa. Dra. Valquiria Hyppolito Barnabe.

1. Sêmen. 2. Caprino. 3. Antioxidante. 4. Espécies reativas de oxigênio. 5. Criopreservação. I. Título. 


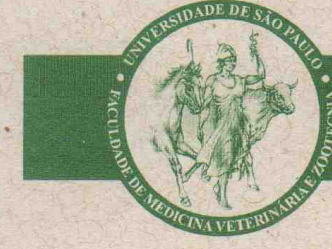

UNIVERSIDADE DE SĀO PAULO

FACULDADE DE MEDICINA VETERINÁRIA E ZOOTECNIA

Comissão de Ética no uso de animais

\section{CERTIFICADO}

Certificamos que o Projeto intitulado "Efeito da adição de antioxidantes enzimáticos na criopreservação do sêmen caprino", protocolado sob o $\mathrm{n}^{\circ}$ 2171/2011, utilizando 12 (doze) caprinos, sob a responsabilidade do(a) Profa. Dra. Valquiria Hyppolito Barnabe, está de acordo com os princípios éticos de experimentação animal da "Comissão de Ética no uso de animais" da Faculdade de Medicina Veterinária e Zootecnia da Universidade de São Paulo e foi aprovado em reunião de 04/5/2011.

We certify that the Research "Effect of the addition of enzymatic antioxidants in cryopreservation of goat semen", protocol number 2171/2011, utilizing 12 (twelve) goats, under the responsibility Profa. Dra. Valquiria Hyppolito Barnabe, agree with Ethical Principles in Animal Research adopted by "Ethic Committee in the use of animals" of the School of Veterinary Medicine and Animal Science of University of São Paulo and was approved in the meeting of day 05/04/2011.

São Paulo, 05 de maio de 2011.

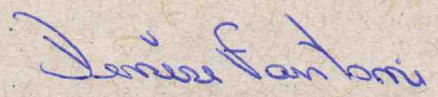

Profa. Dra. Denise Tabacchi Fantoni

Presidente 


\section{FOLHA DE AVALIAÇÃO}

Nome: SILVA, Rodrigo Otávio Correia

\section{Título: Efeito da adição de antioxidantes enzimáticos na criopreservação do sêmen caprino}

Dissertação apresentada ao Programa de Pós-Graduação em Reprodução Animal da Faculdade de Medicina Veterinária e Zootecnia da Universidade de São Paulo para obtenção do título de Mestre em Ciências

Data:

\section{Banca Examinadora:}

Prof.Dr Instituição:

Assinatura: Julgamento:

Prof.Dr Instituição:

Assinatura: Julgamento:

Prof.Dr. Instituição:

Assinatura: Julgamento: 


\section{Dedicatória}

Dedico este trabalho e todos os outros sucessos da minha vida aos meus Pais, José Walter da Silva e Maria Rosa Correia da Silva, que sem ter como descrever o amor que eles sempre me deram, acreditaram em mim e sempre me apoiaram desde os meus seis meses e meio de gestação. Pai e Mãe Amo vocês!

Aos meus dois grandes amigos que Deus me deu na forma de Irmãos, JUCS e MACS, muito obrigado pelo apoio moral, intelectual e financeiro, quando sempre precisei.

Ao meu Tesouro que tenho dentro de casa em Poços de Caldas formado pela minha Super amiga, companheira, e esposa Verena Brunckhorst e aos meus Filhotes Arthur e Augusto que são responsáveis pelo brilho dos meus olhos; Vê muito obrigado por cuidar do nosso tesouro nos dias que estive fora e nas horas de dificuldade. Amo Vocês!

A minha Grande Rainha Vó Guiomar, que eu tenho um carinho todo especial e a todos os meus familiares que fizeram parte da formação do meu caráter. Os SILVAS e OS CORREIAS muito obrigado pelo carinho. 
As Cabras

\section{Agradecimentos}

Aos meus Pais e Irmãos pelo apoio em tudo, inclusive o financeiro muitas vezes!

Aos meus amigos de fé que sei que sempre posso contar e que são os verdadeiros responsáveis pelo meu Mestrado e que me acolheram em um novo Laboratório Marcílio Nichi e Eduardo Gualtieri de Andrade Perez.

Marcilhão muito obrigado pelos ensinamentos infinitos e pelo companheirismo e por ser o meu Co-orientador informal;

Brownzito você mais do que ninguém sabe que sem a sua ajuda esse mestrado não saia, fico devendo mais essa pra você e pra sua família, valeu cara!

A Professora Doutora Vaquiria Hyppolito Barnabe, pela confiança e paciência para me ensinar e orientar em toda trajetória do meu mestrado, e por ter me acolhido de prontidão na hora mais difícil da minha Pós-graduação; Professora muito obrigado e desculpe as minhas brincadeiras.

Ao Professor Renato Campanarut Barnabe, pela oportunidade de conviver com umas das pessoas mais ilustres que eu conheço, Grande Mestre da Reprodução 
Animal, sempre vou lembrar das nossas horas de conversas sobre a veterinária. Muito Obrigado.

Aos meus Amigos da Família L.A. que fomos realmente uma família, brigando, consolando, apoiando, nos divertindo, viajando e trabalhando junto, o meu muito obrigado a todos; Paola mais conhecida como a "chefa" valeu todo apoio e as horas de força que você me deu segurando nossa barra; Andressa, sempre a disposição valeu mesmo a ajuda; Mariana valeu as piadas, Roberta Japa, Diego ditador oficial de tabelas da minha dissertação, Tala, Dani, valeu pelo companheirismo.

João Rafael e Carol, amigos de longa data muito obrigado pelo apoio, pelas risadas e pelos jantares, Carol agradece sua mãe pelos Almoços e Jantares que ela nos ofereceu e em especial o Bacalhau...Divino.

A toda Galera do VRA Everton (JESUS), Paulão (PVC), Juliano (churrasqueiro) e Renata (SCSA), Mari (Chumbada) e Carboxi muito obrigado pelas horas de entretenimento grátis. E A Renata um obrigado especial pelo meu SCSA das Amostras, Valeu.

A Professora Doutora Mayra, pelas aulas e pelas palavras de força e confiança quando tudo parecia que era o fim e na verdade estava apenas começando, muito obrigado. 
A Harumi, nossa se a mesa da Harumi falasse, bom muito obrigado pelas milhares de ajudas e emails lembrando de prazos e compromissos, e por responder a todas as minhas milhares de perguntas sobre a Pós-graduação, um verdadeiro "Horáculo do VRA", muito obrigado mesmo pelo apoio e pasiência.

Ao Professor Doutor Marcelo, Presidente da Pós-Graduação em Reprodução, muito obrigado pelo apoio importantíssimo e pelas conversas que foram poucas mais mudaram a minha vida. Valeu mesmo!

Ao Professor Doutor Pietro, pelos valiosos ensinamentos e pela honra do convívio.

Aos amigos Zé Nélio e seu Irmão Figura, Manuel, Gabriel, Alê, Robertinha, Rodrigo (Buda), Lindsay, Júlia e alguns que eu sei que estou esquecendo, valeu gente!

Ao Professor Doutor Ed Houffman, pelas horas de amizade e ensinamento sem dúvida um dos melhores professores que já tive, e pode esperar que e minha cerveja artesanal vai sair! Depois levo uma pessoalmente pra você em Pirassununga.

Ao Professor Doutor Rubens Arruda, pelos ensinamentos e amizade e pelo apoio nos meus problemas em Pirassununga, Rubão muito obrigado. 
Ao Zé Rodrigo, grande amigo Síndico da Casa do VRA, parceiro nas melhores e piores horas, valeu mesmo!!! Depois te dou uma carona pra Descalvado.

Ao pessoal do VRA de Pirassununga, Pati, Andres (Colombiano), Fabian (Paraguayo), Aline (Alemã), Milton Maturama, André (Simprão), Professor Doutor Mario Binelli, Zé Maria, Márcio e João sempre juntos pra cuidar das cabritas, a Edina pelo Café e os Bolos deliciosos, ao Bigode Motorista, e todos que eu esqueci neste momento. Valeu!

Ao pessoal do VRA de São Paulo, Dona Sílvia pelos cafezinhos que reanimavam, a todos os funcionários Belau, Miguel, Maria Amélia, Thaís, enfim a todos que de alguma forma fizeram parte deste trabalho.

Ao meu Note Book que resistiu bravamente até ontem, quebrou ontem mais agora já acabei, valeu a força!

A minha "Harley da China" 150cc, que me aguentou e me fez companhia pelos $7.500 \mathrm{~km}$ percorridos no meu Mestrado. 
A "Craudinha" e Maria Roberta amigas de Graduação que sempre quando dava tomávamos uma em Sampa na "Flor do Mor Pará" em Higienópolis.

Ao pessoal do "Feijão de Corda" que proporcionaram horas incríveis de descontração.

Aos meus Sogros, Ingrid e Benhard e aos meus cunhados, Cristhian e Bel, Dirk e Gabi, Jan e Grazi e ao Colin que me aguentaram esses anos mais frequentes em São Paulo, prometo ficar uns tempos sem aparecer!!!

Aos meus Tios Regina e Marcos, Bá, Tio Belmiro e Camila por estarem a disposição para cuidar dos meus filhotes Arthur e Guto, quando nem eu ou a Vê podíamos. Vocês foram demais!!!

As Cabras e aos Bodes que me serviram no experimento e por serem responsáveis pela minha paixão pela caprinocultura.

Ao Rancho das Cabras sem palavras pra descrever as alegrias de tantos Campeonatos em exposições pelo Brasil afora e banhos de leite nos infinitos torneios leiteiros e pelas experiências nas dificuldades de ser Produtor Rural no Brasil. 
A Professora Doutora Anneliese de Souza Traldi(Kiky), por abrir as portas da USP e pelos muitos ensinamentos sobre caprinovinocultura.

Ao Bob (cão da Família) e ao Pé de Pano (Cavalo da Família), que meu filho Arthur falou para não esquecer deles.

Em fim a todos que eu não citei mas me ajudaram, e como podemos ver é mesmo uma verdade que "Ninguém faz Sucesso Sozinho"!

A CAPES agência financiadora deste trabalho através da Bolsa

Muito Obrigado a Todos! 
É em alta temperatura que o Ferro vira Aço"

(José Walter da Silva) 


\section{RESUMO}

SILVA, R. O. C. Efeito da adição de antioxidantes enzimáticos na criopreservação do sêmen caprino. [Effect of enzymatic antioxidants on goat cryopreserved semen]. 2011. $83 \mathrm{f}$. Dissertação (Mestrado em Ciências) - Faculdade de Medicina Veterinária e Zootecnia, Universidade de São Paulo, São Paulo, 2011.

A caprinocultura no Brasil vem crescendo consideravelmente nos últimos anos. No entanto, este crescimento é limitado pela qualidade espermática pós-descongelamento, o que inviabilizaria a utilização de biotecnologias aplicadas à reprodução (e.g., inseminação artificial e transferência de embriões). Um dos motivos para a queda na qualidade espermática pós-descongelação é o ataque das espécies reativas de oxigênio (ROS), que podem levar a danos em membrana, acrossomo, mitocôndria e DNA. Uma alternativa para a melhora na qualidade espermática de amostras criopreservadas de caprinos seria o tratamento do meio diluidor com a antioxidantes. No entanto, é fundamental identificar a espécie reativa de oxigênio mais deletéria ao sêmen de caprinos para determinar o antioxidante ideal. O objetivo do presente estudo foi identificar a ROS mais deletéria ao sêmen de caprinos e, com isso, tratar o diluidor com antioxidantes específicos para a destruição da mesma. No experimento 1, amostras espermáticas de 12 bodes foram submetidas á incubação com 3 sistemas de produção de ROS e um subproduto da peroxidação de lipídeos, conhecida por também levar a danos oxidativos. As amostras espermáticas foram submetidas a incubação com xantina $(20 \mathrm{mM})$ e xantina oxidase (ânion superóxido), sulfato de ferro $(4 \mathrm{mM})$ e ascorbato $(20 \mathrm{mM}$ Radical hidroxila), peróxido de hidrogênio $\left(\mathrm{H}_{2} \mathrm{O}_{2} ; 20 \mathrm{mM}\right)$ e malondialdeído (20 mM). Após a incubação as amostras espermáticas foram avaliadas quanto a morfologia, motilidade, membrana (eosina/nigrosina), acrossomo (Rosa Bengala/ Fast Green), mitocôndria (3,3 diaminobenzidina) e substâncias reativas ao ácido tiobarbitúrico (TBARS, avalia a susceptibilidade do espermatozóide ao estresse oxidativo). Os resultados do experimento 1 indicaram que a ROS mais deletéria ao espermatozóide caprino é o $\mathrm{H}_{2} \mathrm{O}_{2}$, que levou a danos de membrana plasmática e mitocôndria. Assim, no Experimento 2, o diluidor para a criopreservação do sêmen caprino foi suplementado com catalase e Glutationa Peroxidase (GPx), antioxidantes enzimáticos responsáveis pela destruição do $\mathrm{H}_{2} \mathrm{O}_{2}$. A análise estatística 
dos dois experimentos foi realizada através do SAS system for Windows. Os resultados do experimento 2 não revelaram efeitos benéficos para nenhuma das variáveis e com a utilização de ambos os antioxidantes. De fato, a catalase apreesntou efeitos deletérios à membrana plasmática das amostras criopreservadas com $240 \mathrm{UI} / \mathrm{mL}$ de catalase quando comparadas ao controle $(13,42 \pm 2,96 \%$ e $25,08 \pm 4,80 \%$ de espermatozóides com membrana íntegra, respectivamente). De fato, estudos anteriores indicam que as concentrações de catalase em sêmen de caprinos são extremamente baixas, o que indicaria que o tratamento com as dosagens utilizadas de catalase pode ter sido excessivo. Além disto, diferentes antioxidantes aparentemente atuam em diferentes regiões do espermatozóide, sendo que, apenas a combinação de diferentes antioxidante poderia ser eficiente. Por outro lado, os resultados do Experimento 1 foram obtidos em amostras frescas, sendo que provavelmente, em amostras criopreservadas, a espécie reativa mais deletéria poderia ser outra.

Palavras-chave: Sêmen. Caprino. Antioxidante. Espécies reativas de oxigênio. Criopreservação. 


\begin{abstract}
SILVA, R. O. C. Effect of enzymatic antioxidants on goat cryopreserved semen. [Efeito da adição de antioxidantes enzimáticos na criopreservação do sêmen caprino]. 2011. $83 \mathrm{f}$. Dissertação (Mestrado em Ciências) - Faculdade de Medicina Veterinária e Zootecnia, Universidade de São Paulo, São Paulo, 2011.
\end{abstract}

The goat production in Brazil has grown considerably in recent years. However, this growth is limited by the post-thaw sperm quality, which would impais the use of biotechnologies applied to reproduction (e.g., artificial insemination and embryo transfer). One reason for the decline in sperm quality after thawing is the attack of reactive oxygen species (ROS), which can lead to damage of membrane, acrosome, mitochondria and DNA. An alternative to improve the quality of cryoprerved goat sperm samples would be the treatment of the extender with antioxidants. However, it is crucial to identify the reactive oxygen species more deleterious to semen of goats to determine the ideal antioxidant. The aim of this study was to identify the ROS more deleterious to semen of goats and thereby to treat the extender with specific antioxidants for the destruction of this ROS. In experiment 1, sperm samples from 12 goats were incubated with 3 systems of production of ROS and a by-product of lipid peroxidation, known to also lead to oxidative damage. The sperm samples were subjected to incubation with xanthine $(20 \mathrm{mM})$ and xanthine oxidase (superoxide anion), iron sulfate (4 $\mathrm{mM}$ ) and ascorbate (20mM-hydroxyl radical), hydrogen peroxide ( $\mathrm{H} 2 \mathrm{O} 2,20 \mathrm{mM}$ ) and malondialdehyde $(20 \mathrm{mM})$. After incubation the samples were evaluated for sperm morphology, motility, membrane (eosin / nigrosin), acrosome (Rose Bengal / Fast Green), mitochondria (3.3 diaminobenzidine) and thiobarbituric acid reactive substances (TBARS, assesses the susceptibility of sperm to oxidative stress). The results of experiment 1 indicated that ROS most deleterious to the goat sperm is the $\mathrm{H}_{2} \mathrm{O}_{2}$, especially due to damages to the plasma membrane and mitochondria. Thus, in Experiment 2, the extender for cryopreservation of goat semen was supplemented with catalase and glutathione peroxidase (GPx), enzymatic antioxidants responsible for the destruction of $\mathrm{H}_{2} \mathrm{O}_{2}$. Statistical analyses were performed using the SAS system for Windows. The results of experiment 2 revealed no 
beneficial effects of the use of neither catalase oor GPx. In fact, catalase showed deleterious effects on the plasma membrane of cryopreserved samples; Samples treated with $240 \mathrm{IU} / \mathrm{mL}$ of catalase showed a lower percentage of sperm with intact membrane when compared with controls (13.42 $\pm 2.96 \pm 4.80 \%$ and $25.08 \%$, respectively $)$. In fact, previous studies indicate that concentrations of catalase in semen of goats are very low, which indicates that catalase treatment with the dosages used in the present study may have been excessive. Apparently different antioxidants work in different regions of the sperm, and only the combination of different antioxidant could be effective. Moreover, the results of Experiment 1 were obtained in fresh samples, and probably, in cryopreserved samples, other ROS could be the most deleterious.

Keywords: Semen. Goat. Antioxidant. Reactive oxygen species. Cryopreserved. 


\section{LISTA DE FIGURAS}

Figura 1 - Espermatozóides com coloração POPE........................................ 52

Figura 2 - Espermatozóides corados com Eosina / Nigrosina............................. 53

Figura 3 - Grau de coloração da peça intermediária da célula espermática............................................................................... 5

Figura 4 - Correlação entre as taxas de espermatozóides com membrana e acrossomo íntegros, espermatozóides com atívidade mitocondrial DAB I, DAB II, DAB III e DAB IV, e susceptibilidade ao estresse oxidativo (TBARS) em sêmen de caprinos submetido à indução do estresse oxidativo com diferentes espécies reativas de oxigênio. Poços de Caldas, MG

Figura 5 - Formulação das espécies reativas de oxigênio (EROs), modificado de Chabot et al., 1998.

Figura 6 - Correlação entre as taxas de espermatozóides com membrana e acrossomo íntegros, espermatozóides com atívidade mitocondrial DAB I, DAB II, DAB III e DAB IV, e susceptibilidade ao estresse oxidativo (TBARS) em sêmen criopreservado de caprinos suplementado com diferentes concentrações de catalase. Poços de Caldas, MG.

Figura 7 - Correlação entre as taxas de espermatozóides com membrana e acrossomo íntegros, espermatozóides com atívidade mitocondrial DAB I, DAB II, DAB III e DAB IV, e susceptibilidade ao estresse oxidativo (TBARS) em sêmen criopreservado de caprinos suplementado com diferentes concentrações de glutationa peroxidase. Poços de Caldas, MG. 


\section{LISTA DE TABELAS}

Tabela 1 - Efeitos das induções com diferentes espécies reativas de oxigênio e do subroduto da peroxidação lipídica (Ânion: ânion superóxido; $\mathrm{H}_{2} \mathrm{O}_{2}$ : peróxido de hidrogênio; Hidroxila: radical hidroxila; MDA: malondialdeído) nas alterações morfológicas em sêmen de caprinos. Poços de Caldas, MG.......

Tabela 2 - Efeitos das induções com diferentes espécies reativas de oxigênio e do subproduto da peroxidação lipídica (Ânion: ânion superóxido; $\mathrm{H}_{2} \mathrm{O}_{2}$ : peróxido de hidrogênio; Hidroxila: radical hidroxila; MDA: malondialdeído) nas taxas de anormalidades morfológicas espermáticas maiores e menores em sêmen de caprinos. Poços de Caldas, MG

Tabela 3 - Efeitos das induções com diferentes espécies reativas de oxigênio e do subproduto da peroxidação lipídica (Ânion: ânion superóxido; $\mathrm{H}_{2} \mathrm{O}_{2}$ : peróxido de hidrogênio; Hidroxila: radical hidroxila; MDA: malondialdeído) nas taxas de espermatozóides com membrana e acrossomo íntegros, espermatozóides com atívidade mitocondrial DAB I, DAB II, DAB III e DAB IV, e susceptibilidade ao estresse oxidativo (TBARS) em sêmen de caprinos. Poços de Caldas, MG...... 61

Tabela 4 - Efeitos do tratamento de amostras espermáticas caprinas criopreservadas com diferentes concentrações de catalase $(0,60,120$ e $240 \mathrm{UI} / \mathrm{mL}$ ) nas taxas de anormalidades espermáticas. Poços de Caldas, MG.

Tabela 5 - Efeitos do tratamento de amostras espermáticas caprinas criopreservadas com diferentes concentrações de catalase $(0,60,120$ e $240 \mathrm{UI} / \mathrm{mL}$ ) nas taxas de anormalidades morfológicas espermáticas maiores e menores.

Tabela 6 - Efeitos do tratamento de amostras espermáticas caprinas criopreservadas com diferentes concentrações de catalase $(0,60,120$ e $240 \mathrm{UI} / \mathrm{mL}$ ) nas taxas de espermatozóides com membrana e acrossomo íntegros, espermatozóides com atívidade mitocondrial DAB I, DAB II, DAB III e DAB IV, e susceptibilidade ao estresse oxidativo (TBARS). Poços de Caldas, MG. 
Tabela 7 - Efeitos do tratamento de amostras espermáticas caprinas criopreservadas com diferentes concentrações de glutationa peroxidase $(0,1,5$ e $10 \mathrm{UI} / \mathrm{mL})$ nas taxas de anormalidades espermáticas. Poços de Caldas, MG.

Tabela 8 - Efeitos do tratamento de amostras espermáticas caprinas criopreservadas com diferentes concentrações de glutationa peroxidase $(0,1,5$ e $10 \mathrm{UI} / \mathrm{mL})$ nas taxas de anormalidades morfológicas espermáticas maiores e menores.

Tabela 9 - Efeitos do tratamento de amostras espermáticas caprinas criopreservadas com diferentes concentrações de glutationa peroxidase $(0,1,5$ e $10 \mathrm{UI} / \mathrm{mL})$ nas taxas de espermatozóides com membrana e acrossomo íntegros, espermatozóides com atívidade mitocondrial DAB I, DAB II, DAB III e DAB IV, e susceptibilidade ao estresse oxidativo (TBARS). Poços de Caldas, MG 


\section{LISTA DE SÍMBOLOS}

r coeficiente de correlação de Pearson

g força centrípeta

o Graus

${ }^{\circ} \mathrm{C} \quad$ graus Celsius

$=\quad$ Igual

$\log _{10} \quad$ logarítmo na base 10

$>\quad$ maior que

mais ou menos

® marca registrada

$<\quad$ menor que

$\mu \mathrm{M} \quad$ Micromolar

$\mu \mathrm{g} \quad$ Micrograma

$\mu \mathrm{L} \quad$ Microlitro

mg Miligrama

$\mathrm{mL} \quad$ Mililitro

mm Milímetros

mM Milimolar 
M Molar

ng Nanograma

nm Nanômetro

p nível de significância

$\% \quad$ Porcentagem

$\mathrm{pH}$ potencial hidrogênio iônico

$\mathrm{kg} \quad$ Quilograma 


\section{SUMÁRIO}

1 INTRODUÇÃ

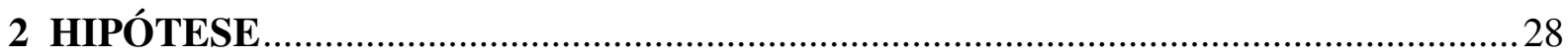

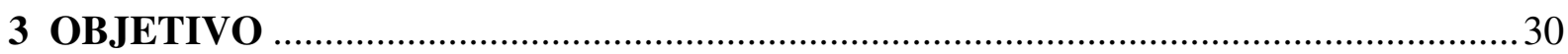

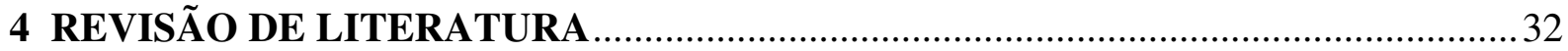

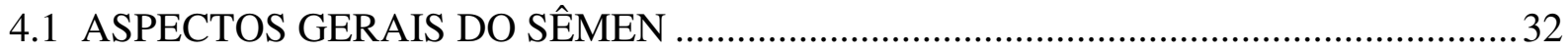

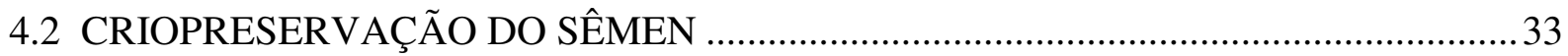

4.3 TÉCNICAS DE AVALIAÇÃO DA INTEGRIDADE ESPERMÁTICA ..........................35

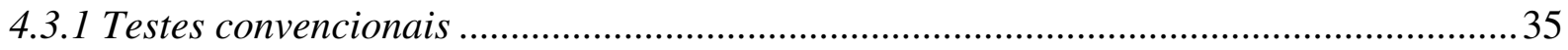

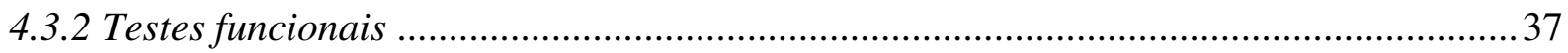

4.3.2.1 Integridade da membrana plasmática .................................................................. 37

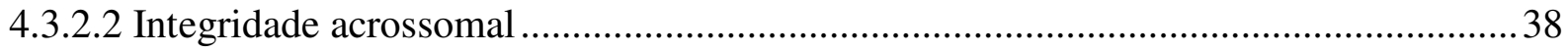

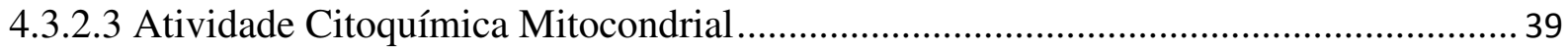

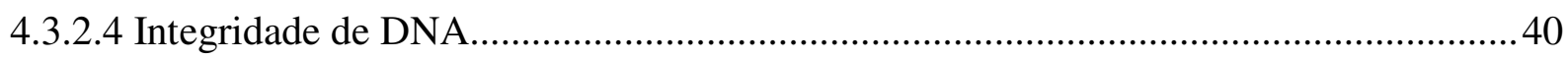

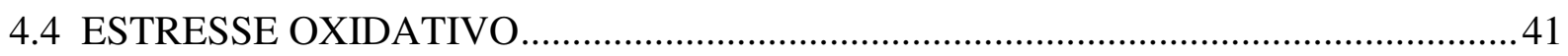

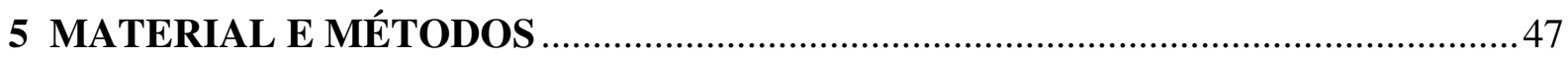

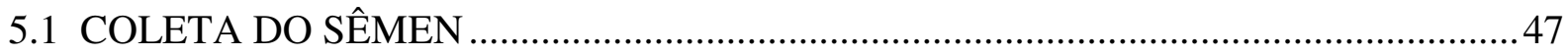

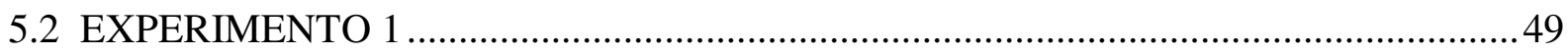

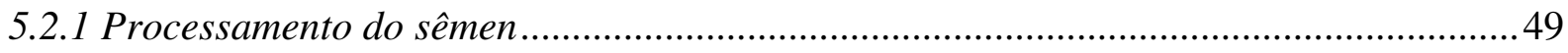

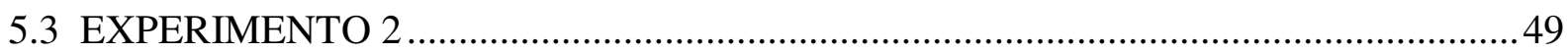

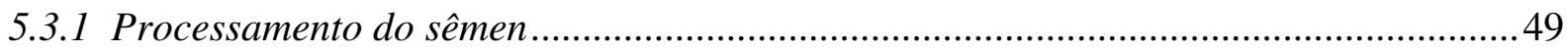

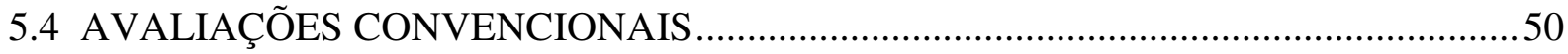

5.4.1 Avaliação da motilidade espermática .........................................................................50

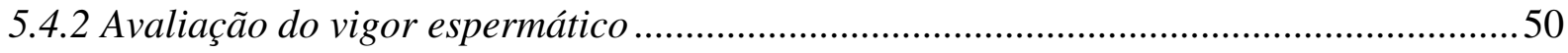

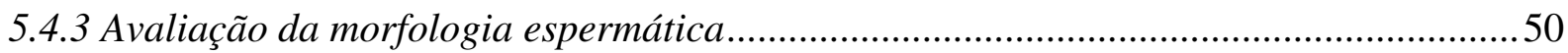




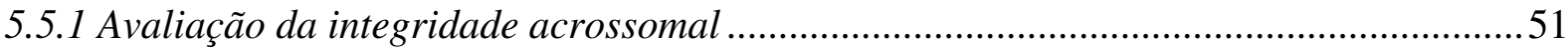

5.5.2 Avaliação da integridade da membrana plasmática ...................................................52

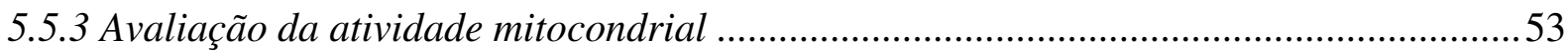

5.5.4 Ensaio da estrutura da cromatina espermática (SCSA)...............................................54

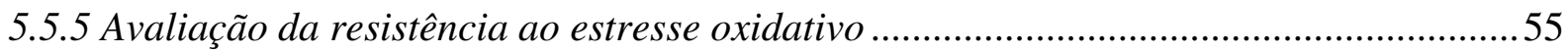

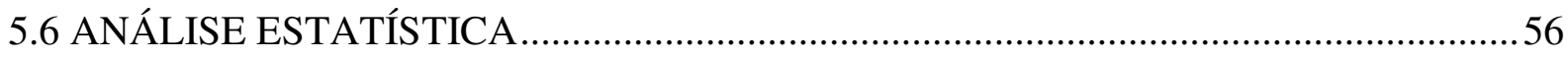

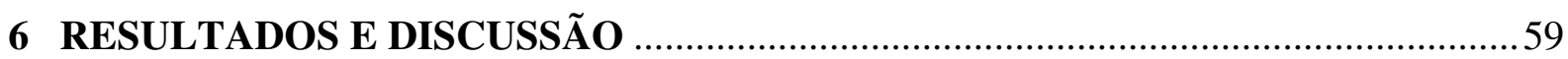

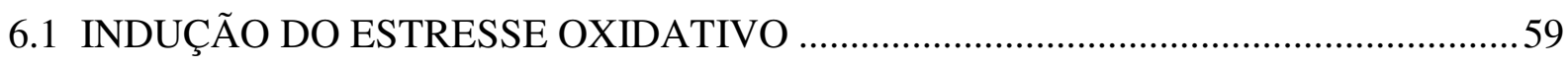

6.2 EFEITO DO TRATAMENTO COM CATALASE ......................................................64

6.3 EFEITO DO TRATAMENTO COM GLUTATIONA PEROXIDASE ............................68

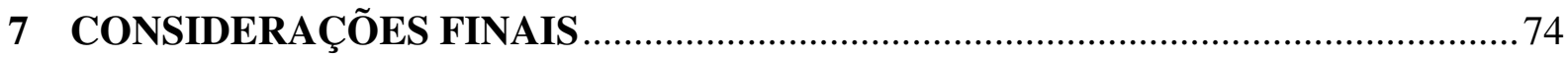

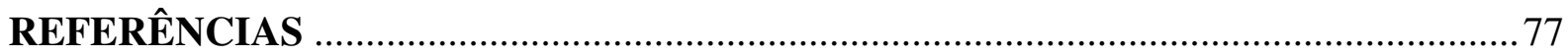


Introdução 


\section{INTRODUÇÃO}

Nas últimas décadas a caprinocultura nacional vem crescendo consideravelmente, sobretudo em regiões que a tradição em criação de caprinos não é muito antiga e o perfil dos criadores está sofrendo mudanças consistentes. Observa-se uma transição da atividade de subsistência para um agronegócio, justificando assim novos investimentos em produtividade, melhoramento genético e em novas tecnologias de produção e reprodução.

A falta da aplicação adequada de biotécnica reprodutiva nos rebanhos pode comprometer a lucratividade da exploração por impedir que o potencial produtivo máximo do rebanho seja alcançado. Dessa maneira a multiplicação dos indivíduos geneticamente interessantes para a produção fica prejudicada levando sérios prejuízos ao produtor, que não consegue o melhoramento do seu rebanho da melhor maneira para diluir os custos fixos de produção.

Biotécnicas como a inseminação artificial e a transferência de embriões são empregadas, cada vez mais freqüentemente na caprinocultura nacional, visando a excelência dos rebanhos e a multiplicação de animais geneticamente superiores, possibilitando uma produção mais barata e rentável.

A inseminação artificial (IA), desenvolvida para o manejo reprodutivo e melhoramento genético dos animais, pois possibilita a dispersão de material genético, favorece testes de progênie, implanta programas de controle zootécnico utilizando reprodutores de relevância produtiva, além de prevenir enfermidades reprodutivas (HAFEZ; HAFEZ, 2000).

A necessidade de produzir grande número de descendentes com sêmen de bodes oriundos de criatórios distantes estimulou o desenvolvimento de técnicas de transporte e estocagem de sêmen (SALAMON; MAXWELL, 2000).

Com a implantação de programas de inseminação artificial nos atuais rebanhos, é de extrema importância o aperfeiçoamento da criopreservação de células espermáticas. Técnica esta que possibilita a utilização posterior de sêmen oriundo de reprodutores de localidades distantes ou pós morten, uma vez que o sêmen estocado à $-196^{\circ} \mathrm{C}$ (temperatura do nitrogênio líquido) permanece viável por tempo indefinido (HAFEZ; HAFEZ, 2000).

A criopreservação do sêmen caprino, assim como todas as espécies de produção domésticas, é um dos gargalos da estocagem de gametas e inseminação artificial. 
O processo de congelação promove danos físicos e metabólicos aos espermatozóides provenientes de estresse oxidativo. Recentemente o estudo da associação entre as espécies reativas ao oxigênio e a função das células germinativas tem sido reportada pela ocorrência de radicais livres do oxigênio no sêmen, afetando adversamente a viabilidade dos espermatozóides.

O estresse oxidativo é o resultado de um desequilíbrio entre a concentração de antioxidantes (agentes redutores) e concentração radicais livres (agentes oxidantes); este desequilíbrio, muitas vezes, ocorre em virtude de exacerbação da produção de espécies reativas de oxigênio (ROS) (NICHI, 2003).

Assim, a adição de anti-oxidantes nos meios de criopreservação é uma alternativa promissora. Estudos realizados incubando amostras de sêmen com diferentes Espécies Reativas de Oxigênio, demonstraram que o sêmen de bodes é particularmente suceptível ao peróxido de hidrogênio (SILVA et al, 2010). Portanto, é possível que a adição dos antioxidantes enzimáticos catalase e glutationa peroxidase, responsáveis pela destruição do peróxido de hidrogênio, apresentem efeitos positivos e relevantes sobre a qualidade espermática após a criopreservação. 
Hipótese 


\section{HIPÓTESE}

A maior ou menor susceptibilidade do espermatozóide caprino ao estresse oxidativo depende das diferentes espécies reativas de oxigênio, sendo que o tratamento com antioxidantes específicos para a destruição das espécies reativas mais lesivas melhora a qualidade espermática após a criopreservação. 
Objetivo 


\section{OBJETIVO}

O objetivo do presente trabalho é identificar a espécie reativa de oxigênio mais lesiva ao espermatozóide caprino e se a adição de antioxidantes específicos podem proteger as membranas plasmática e acrossomal, a atividade mitocondrial a integridade de cromatina e o status oxidativo de espermatozóides durante a cripreservação. 
$\underline{\text { Revisão de Literatura }}$ 


\section{REVISÃO DE LITERATURA}

Nas últimas décadas a caprinocultura brasileira, atingiu um efetivo de 9.850 milhões de caprinos segundo o Instituto Brasileiro de Geografia e estatística (IBGE, 2009), produzindo cada vez mais produtos de origem caprina como leite, carne e pele, conquistando o $15^{\circ}$ lugar na produção mundial leite de cabra, produzindo mais de 140.000 toneladas (FAO, 2006).

\subsection{ASPECTOS GERAIS DO SÊMEN}

A colheita de sêmen na espécie caprina é realizada usualmente através da vagina artificial, podendo ser utilizada a técnica da eletroejaculação, ou ainda a menos comum, a cirúrgica por acesso à cauda do epidídimo (KUNDU et al., 2002).

Os espermatozóides são células especializadas, que possui limitada capacidade de reparação (MCKINNON; VOSS, 1993) e são formadas dentro dos túbulos seminíferos dos testículos (FRANDSON; WILKE; FAILS, 2005; CUNNINGHAM; KLEIN, 2008). Desordens na espermatogênese podem ocasionar alterações nos parâmetros dos espermatozóides no ejaculado ou até provocando quadros de infertilidade (HAFEZ, 2004; CUNNINGHAM; KLEIN, 2008; GONÇALVES; FIGUEIREDO; FREITAS, 2008). Para que seja considerado qualitativamente viável e potencialmente fértil é necessário que, o espermatozóide possua morfologia, atividade metabólica e membranas normais. A presença de membranas íntegras é pré-requisito para que os eventos relacionados ao processo de fertilização, como a capacitação espermática, penetração nos revestimentos do ovócito, ligação à zona pelúcida e fusão com o oócito possam ocorrer (ARRUDA et al., 2005).

Histologicamente, a célula espermática está subdividida em três segmentos: cabeça, corpo e cauda (GONÇALVES; FIGUEIREDO; FREITAS, 2008). A membrana espermática é composta basicamente de uma bicamada de lipídeos, principalmente os ácidos graxos poli- 
insaturados, em especial o ácido decosa-hexanóico (DHA), que são de grande importância celular, pois conferem as características de fluidez, necessária para os eventos associados à fertilização, e permeabilidade à membrana (HAFEZ, 2004; CUNNINGHAM; KLEIN, 2008; GONÇALVES; FIGUEIREDO; FREITAS, 2008). Essa fluidez depende da temperatura, teor de colesterol e seu grau de saturação. Colesteróis saturados garantem maior rigidez, enquanto os insaturados conferem maior fluidez às membranas (OLLERO; POWERS; ALVAREZ, 2000).

O sêmen caprino apresenta particularidades que o diferencia de outras espécies, sendo a mais importante a síntese e secreção de enzimas pelas glândulas bulbo uretrais, liberadas no plasma seminal (BEZERRA, 2010). De acordo com esses autores, essas enzimas hidrolizam lecitina, fosfolipídios mais abundante nas membranas plasmáticas, em lisolecitinas e ácidos graxos, que são altamente tóxicos para os espermatozóides. Dessa forma, as composições enzimáticas do sêmen e dos diluidores seminais do bode assumem grande importância no processo de conservação do sêmen desta espécie.

\subsection{CRIOPRESERVAÇÃO DO SÊMEN}

Para o sucesso da fertilização é necessário a disponibilidade de gametas viáveis e funcionalmente normais, tanto in vivo quanto in vitro. A criopreservação de gametas e embriões tornou-se um procedimento complementar e essencial para a aplicação de biotécnicas como inseminação artificial, fertilização in-vitro, transferência de embriões e engenharia genética (PARKS, 1985).

A criopreservação permite o armazenamento de material genético por tempo indeterminado sob baixas temperaturas (CARDOSO et al., 2005). Esse processo é constituído de diluição, refrigeração, congelação, armazenamento e descongelação (HAMMERSTEDT; GRAHAM; NOLAN, 1990). Durante o resfriamento, os colesteróis se modificam de fase líquida para fase gel, e durante esta etapa podem ocorrer danos nas estruturas espermáticas devido ao choque frio que pode provocar um rearranjo nas ultra-estruturas celulares 
(OLLERO et al., 1998). A susceptibilidade ao choque frio se desenvolve quando o espermatozóide atravessa o epidídimo (WATSON, 1995). Os protocolos de criopreservação que vêem sendo utilizados submetem as células espermáticas a situações de estresse, comprometendo sua viabilidade, apesar da tentativa de preservação das estruturas espermáticas e minimização dos danos causados pelo choque frio através da interação entre diluidor, crioprotetor, curvas de refrigeração, congelação e descongelação (WATSON, 2000; YOSHIDA, 2000).

No processo de congelação, a faixa de temperatura considerada crítica para danos no espermatozóide, fica entre -15 e $-50^{\circ} \mathrm{C}$. Quando o sêmen atravessa esta faixa crítica, a atividade metabólica cessa e as células permanecem inativas (HOLT, 2000). Tradicionalmente, o sêmen caprino envasado em palhetas é descongelado a $37^{\circ} \mathrm{C}$ durante 12 a 30 s (CABRERA et al., 2005; PURDY, 2006).

Parks e Graham (1992) observaram que o tipo de fosfolipídio predominante na membrana também influenciava na sensibilidade ao choque frio e que quanto maior o conteúdo de proteína da membrana, mais baixa a resistência ao choque frio.

Estudos com bovinos demonstraram que a criopreservação espermática está associada ao aumento da geração de espécies reativas de oxigênio (BILODEAU et al., 2000). Peris et al., em 2007 observou a diminuição na qualidade espermática de sêmen criopreservado de ovinos, em todas as características avaliadas, utilizando as técnicas de estabilidade de DNA (SCSA), peroxidação lipídica de membranas (LPO) e características funcionais, como motilidade (CASA), viabilidade (eosina/nigrosina) e integridade de acrossomo (CTC).

Em caprinos a técnica de criopreservação vem demonstrando a susceptibilidade a danos na célula espermática devido ao processo de congelação (BEZERRA, 2010). 


\subsection{TÉCNICAS DE AVALIAÇÃO DA INTEGRIDADE ESPERMÁTICA}

A falta do procedimento ou critérios da avaliação seminal poderá afetar a fertilidade de todo um rebanho, trazendo prejuízos econômicos. Em programas de IA (inseminação artificial), IATF (inseminação artificial em tempo fixo), TETF (transferência de embrião em tempo fixo) e TE (transferência de embrião), os prejuízos podem ser ainda maiores, visto que os gastos com fármacos para a sincronização dos estros, bem como para a indução da ovulação das fêmeas, além do dispêndio em material, sêmen e tempo (ARRUDA et al., 2005).

Caso haja qualquer alteração no ambiente espermático, seja ela por aumento de temperatura, criopreservação, excesso de radicais livres ou até mesmo escassez de antioxidantes, toda característica estrutural e funcional dos espermatozóides será afetada, resultando em alterações estruturais do espermatozóide e comprometendo profundamente o potencial fertilizante das células (RODRIGUES, 2009).

\subsubsection{Testes convencionais}

Normalmente as avaliações laboratoriais realizadas com o objetivo de estimar o potencial de fertilidade de uma partida de sêmen são: motilidade espermática (\%); vigor (1-5); concentração espermática (milhões/ml); anormalidades espermáticas (\%) e o teste de termoresistência (lento ou rápido) (ARRUDA et al., 2005).

Usualmente, a motilidade e vigor espermáticos são estimados de forma subjetiva, sendo analisados sob microscopia óptica, com uma gota de sêmen entre lâmina e lamínula, estimando-se a porcentagem, apenas visualmente. As anormalidades espermáticas são avaliadas em esfregaços corados ou câmara úmida, em uma avaliação que depende da habilidade do técnico. Entretanto estudos reportam que esse tipo de análise manual é 
impreciso, mesmo quando executado por técnicos experientes (NICHI, 2003; RODRIGUES, 2009).

O caráter móvel dos espermatozóides é um meio facilmente distinguível de determinar seu estado fisiológico, e é amplamente aceito que a boa motilidade é um componente central para a fertilidade normal (TURNER, 2006). A estimativa da porcentagem de células espermáticas exibindo movimento progressivo é a avaliação mais utilizada durante a análise seminal e deve ser superior a 70\%, quando se trata de amostra seminal fresca (FONSECA et al., 1997). No entanto, essa avaliação é considerada, em geral, mais como uma forma de verificar a viabilidade da célula espermática do que predizer sua fertilidade, pois, os espermatozóides podem perder sua capacidade fertilizante, antes mesmo de perder a motilidade (BARROS, 2007).

$\mathrm{Na}$ determinação do vigor estima-se a intensidade dos movimentos que acaba influenciando a velocidade. $\mathrm{O}$ mesmo varia de 0 , sem movimentos, até 5 com movimento muito intenso (FONSECA et al., 1997). Tal fato faz com que as avaliações da motilidade e vigor por meio visual sejam consideradas como um método subjetivo, mesmo quando feita por técnicos bem treinados, que apresentam uma boa repetibilidade e confiança nas avaliações (RODRIGUES, 2009).

A concentração espermática é determinada pela quantidade de espermatozóides presentes em um dado volume de ejaculado, sendo geralmente expressa em $10^{6} / \mathrm{ml}$ (milhões/ml); o número total de espermatozóides no ejaculado obtém-se pela multiplicação da concentração espermática pelo volume (GONÇALVES; FIGUEIREDO; FREITAS, 2008).

Uma determinação acurada do número de espermatozóides por volume de ejaculado especifica o número de fêmeas que poderão ser inseminadas. A concentração espermática pode ser realizada através de hemocitômetro, fotocolorímetro ou espectrofotômetro, sendo uma técnica extremamente importante de análise, já que seus parâmetros variam devido a fatores como método e frequência de coleta, idade do reprodutor e saúde testicular (GONÇALVES; FIGUEIREDO; FREITAS, 2008; RODRIGUES, 2009).

Para sêmen congelado também é realizado o teste de termo-resistência (TTR). A técnica consiste em submeter o sêmen, após avaliação de motilidade e vigor, à temperatura de $38^{\circ} \mathrm{C} / 4$ horas (TTR lento) ou $45^{\circ} \mathrm{C} / 1$ hora (TTR rápido), em banho-maria, aproximando às condições em que fica exposto no trato genital das fêmeas em cio (ARRUDA et al., 1992). 
Posteriormente é novamente mensurado motilidade e vigor, devendo manter no mínimo 50\% do valor obtido anteriormente (ARRUDA et al., 1989).

\subsubsection{Testes funcionais}

Os testes funcionais utilizados neste experimento estão descritos a seguir.

\subsubsection{Integridade da Membrana Plasmática}

A membrana plasmática possui um importante papel nos processos de capacitação e fertilização do oócito e sua constituição bioquímica é um dos principais pontos de interesse do estudo da fisiologia e patologia espermática. Teorias sobre a fusão de membranas (oócito/espermatozóide) sugerem que sua fluidez é pré-requisito para a função normal da célula (BARROS, 2007). É responsável ainda, pela manutenção do equilíbrio osmótico e atua como uma barreira mantendo, assim, diferenças de composição entre os meios intra e extracelulares (NICHI, 2003).

Para avaliar a integridade da membrana plasmática é utilizada a coloração de EosinaNigrosina. Esse método de coloração foi descrito por Barth e Oko (1989).

No caso de membranas lesionadas, ocorrem alterações de permeabilidade, onde a eosina consegue penetrar nessas células corando-as de rosa. Os espermatozóides com membranas plasmáticas íntegras não permitem a entrada do corante, contrastando, portanto, com o plano de fundo corado pela nigrosina, apresentando-se branca (BARTH; OKO, 1989).

Para realizar essa coloração, uma alíquota de sêmen deve ser misturada ao corante, na proporção de 1:1, e após, fazer esfregaços sobre lâminas de microscopia. Essas lâminas devem ser analisadas em microscópio convencional sob óleo de imersão em aumento de 1000 
vezes. Deve-se contar 200 células, que devem ser classificadas como células com membrana íntegra (não coradas) e não íntegra (coradas) (BARTH; OKO, 1989).

\subsubsection{Integridade Acrossomal}

O acrossomo é um dos principais componentes da célula espermática, visto ser ele o responsável pela fusão do espermatozóide com o oócito (BARROS, 2007).

Portanto, a integridade acrossomal, bem como a manutenção de suas enzimas são cruciais para que ocorra a fertilização. Dessa maneira, é muito importante aplicar técnicas seguras de avaliação ao se estudar viabilidade espermática (NICHI, 2003).

A avaliação da integridade da membrana acrossomal pode ser feita observando suas alterações morfológicas (microscopia eletrônica) ou através de testes funcionais, lançando-se mão do uso de corantes ou de sondas fluorescentes (RODRIGUES, 2009).

Diante disso, Pope, Zhang e Dresser (1991) desenvolveram um método simples e rápido para a coloração dessa organela, comprovando sua eficácia para a avaliação da integridade acrossomal. Desde então, essa coloração vem sendo cada vez mais utilizada para avaliação da integridade acrossomal de espermatozóides de diversas espécies (NICHI, 2003).

Para realizar essa coloração, uma alíquota de sêmen deve ser misturada ao corante, na proporção de 1:1, e após, fazer esfregaços sobre lâminas de microscopia. Essas lâminas devem ser analisadas em microscópio convencional sob óleo de imersão em aumento de 1000 vezes (POPE, ZHANG E DRESSER, 1991).

Deve-se contar 200 células, que devem ser classificadas como células com acrossoma íntegro (coradas) e não íntegra (não coradas) (POPE, ZHANG E DRESSER, 1991).

- Acrossoma intacto: região acrossomal de coloração lilás, levemente mais escura que a região pós-acrossomal; 
- Acrossoma lesionados: região acrossomal de coloração rosa, levemente mais clara que a região pós-acrossomal.

\subsubsection{Atividade Citoquímica Mitocondrial}

A mitocôndria é responsável por aproximadamente $90 \%$ da produção de energia celular, que ocorre por meio do processo de fosforilação oxidativa. Essa organela também é responsável pela maioria da produção endógena de espécies reativas ao oxigênio (radicais livres), além disso, é considerada a reguladora central da apoptose celular (CÂMARA; GUERRA, 2008).

O conjunto de ações da mitocôndria é comandado por aproximadamente 1000 genes, distribuídos em dois sistemas diferentes presentes nas células de mamíferos que são o genoma nuclear e mitocondrial (CÂMARA; GUERRA, 2008).

A enzima citocromo C-oxidase (CCO), presente nas mitocôndrias dos espermatozóides, possui um papel fundamental no processo de respiração celular e metabolismo energético das células e, além disso, é pré-requisito para as funções osmóticas e sintéticas, motilidade e manutenção da estrutura celular (NICHI, 2009).

A técnica citoquímica, para avaliar a atividade mitocondrial dos espermatozóides, desenvolvida por Hrudka (1987) é baseada na oxidação da 3,3' diaminobenzidina (DAB) pelo Complexo Citocromo $\mathrm{C}$, através de uma reação em cadeia na qual o reagente é polimerizado e se deposita na mitocôndria. Essa deposição pode ser identificada através de microscopia convencional devido à coloração marrom da mitocôndria formada por esse complexo. Para realizar essa técnica, adiciona-se uma alíquota de $25 \mu \mathrm{L}$ de amostra incubada juntamente com $25 \mu \mathrm{L}$ de $\mathrm{DAB}$, a $37^{\circ} \mathrm{C}$, por uma hora. Após a incubação, são confeccionados esfregaços em lâminas de vidro e fixadas em formol a $10 \%$ por 10 minutos. Posteriormente as lâminas são secas ao ar sob proteção da luz. 
A atividade mitocondrial é avaliada segundo descrito por Hrudka (1987), em que as lâminas são observadas em microscópio de contraste de fase, sob aumento de 1000 vezes, em imersão. São contados 200 espermatozóides por lâmina, e são classificados de acordo com o grau de coloração da peça intermediária em 4 classes:

- Classe I: Células espermáticas com peça intermediária totalmente corada indicando alta atividade mitocondrial.

- Classe II: Células espermáticas com mais da metade ou metade dos segmentos corados (ativos) indicando atividade mitocondrial média a alta.

- Classe III: Células espermáticas com menos da metade dos segmentos corados indicando baixa atividade mitocondrial.

- Classe IV: Células espermáticas com peça intermediária totalmente descorada indicando ausência de atividade mitocondrial.

\subsubsection{Integridade de DNA}

Espermatozóides com dano de DNA podem ser capazes de fertilizar o oócito. A questão que permanece é em relação ao efeito que esse dano causa no embrião e no desenvolvimento fetal (SAKKAS; ALVAREZ, 2010).

Quando o DNA espermático apresenta pouca fragmentação, o oócito e o embrião possuem mecanismos capazes de reparar esses danos gerando um indivíduo normal (NICHI, 2003; GASCA, et al., 2007). A habilidade do oócito em reparar um dano de DNA irá depender da qualidade do citoplasma e do genoma deste oócito (SAKKAS; ALVAREZ, 2010).

Um oócito fertilizado por um espermatozóide que apresenta uma alta fragmentação de DNA pode ter como consequência morte embrionária e abortamento (TESARIK; GRECO; 
MENDOZA, 2004) ou aparecimento de doenças congênitas em gerações futuras (NICHI, 2003).

É de extrema importância que sejam realizados testes para avaliar a integridade do DNA espermático, já que estudos demonstram que espermatozóides que possuem organização anormal da cromatina é mais frequente em machos subférteis e inférteis (BARROS, 2007).

Uma hipótese para explicar a fragmentação de DNA seriam as mitocôndrias de células com membrana lesada estariam mais sujeitas a lesões, o que levaria a liberação de fatores próoxidativos e pró-apoptóticos. Caso estas células sejam submetidas a um estresse adicional, ocorreria um ataque mais agressivo ao DNA e mesmo a células vizinhas. Da mesma forma, Blumer et al. (2008) também verificaram uma relação entre fragmentação de DNA e atividade mitocondrial defectiva. Segundo estes autores, existe a uma estreita relação entre a disfunção da atividade mitocondrial causada pelo estresse oxidativo e a fragmentação de DNA

Um dos métodos utilizados para detectar fragmentação do DNA espermático é através da técnica de estabilidade de DNA (SCSA).

\subsection{ESTRESSE OXIDATIVO}

O estresse oxidativo refere-se ao desequilíbrio entre o nível de produção de espécies reativas ao oxigênio (ROS) e o grau de proteção dos mecanismos antioxidantes (BARROS, 2007).

Uma das hipóteses para a diminuição da qualidade do sêmen dos animais submetidos ao estresse térmico é uma maior produção de Espécies Reativas ao Oxigênio (ROS) que são radicais livres (átomos ou moléculas que possuem um ou mais elétrons despareados) (NICHI, 2003; ARRUDA et al., 2005; RODRIGUES, 2009).

O processo de peroxidação lipídica inicia-se na presença de ROS, que ao ter contato com os ácidos decosa-hexanóicos da membrana espermática, retiram um hidrogênio de uma dupla ligação, transformando-o em radical livre, que por sua vez irá agir em outro ácido 
decosa-hexanóico. Esse processo desencadeia a cascata de peroxidação, causando lesões na membrana plasmática, com perda de fluidez e de sua capacidade de regular a concentração intracelular de íons envolvidos no controle do movimento espermático e, por fim, perda da sua função de fertilização (MAIA; BICUDO, 2009). A geração de radicais livres também pode atingir o DNA do núcleo espermático, promovendo fragmentação. Essa fragmentação é comumente observada nos espermatozóides de indivíduos inférteis e há fortes evidências que esses danos mediados pela ação dos radicais livres sejam induzidos por estresse oxidativo (NICHI, 2003).

Em condições de normalidade do metabolismo celular aeróbico, o oxigênio molecular $\left(\mathrm{O}_{2}\right)$ sofre redução, resultando na formação de $\mathrm{H}_{2} \mathrm{O}$. Durante esse processo, são formados intermediários reativos (radicais livres) (MAIA; BICUDO,2009).

Entre as ROS, as mais importantes são o radical hidroxila $\left(\mathrm{OH}^{-}\right)$, o ânion superóxido $\left(\mathrm{O}_{2}{ }^{-}\right)$, o peróxido de hidrogênio $\left(\mathrm{H}_{2} \mathrm{O}_{2}\right)$ e o óxido nítrico $\left(\mathrm{NO}_{2}\right)$ (NICHI, 2003; BARROS, 2007).

O ânion superóxido, gerado a partir de uma molécula de oxigênio pela adição de um elétron, apesar de ser um radical livre, não é altamente reativo, pois não consegue penetrar em membranas lipídicas, ficando restrito ao compartimento onde é produzido. O ânion superóxido parece ser o produto primário do sistema de produção de ROS, gerando o peróxido de hidrogênio após uma reação de dismutase (RODRIGUES, 2009).

A formação de superóxido acontece espontaneamente, especialmente no meio aeróbico, rico em elétrons, próximo à membrana mitocondrial interna, que ocorre devido ao escape de elétrons da cadeia respiratória (NORDBERG; ARNÉR, 2001).

$\mathrm{O}$ peróxido de hidrogênio $\left(\mathrm{H}_{2} \mathrm{O}_{2}\right)$ não é um radical livre, mas é um metabólito do oxigênio extremamente deletério porque participa como intermediário na reação que produz o radical $\mathrm{OH}^{-}$. É gerado a partir da dismutação enzimática do $\mathrm{O}_{2}^{-}$pela superóxido dismutase, tem vida longa e é capaz de atravessar membranas biológicas (MAIA; BICUDO, 2009).

O radical hidroxila é considerado o radical mais reativo em sistemas biológicos, sendo capaz de causar mais danos do que qualquer outra ROS. É formado a partir do peróxido de hidrogênio, em uma reação catalisada por íons metais $\left(\mathrm{Fe}^{++}\right.$ou $\left.\mathrm{Cu}^{+}\right)$, denominada reação de Fenton. $\mathrm{O} \mathrm{OH}^{-}$reage rapidamente com biomoléculas e pode desencadear a peroxidação dos 
lipídios na membrana plasmática do espermatozóide (ARUOMA et al.,1989; RODRIGUES, 2009; NICHI, 2003).

$\mathrm{O}$ óxido nítrico apresenta aspectos similares ao $\mathrm{O}_{2}{ }^{-}$, visto que não reage diretamente com as biomoléculas apesar de seu elétron despareado. $\mathrm{O} \mathrm{NO}^{-}$reage facilmente com outros radicais livres, gerando principalmente radicais menos reativos, funcionando então, como um antioxidante. Porém, se $\mathrm{O}_{2}^{-}$for produzido em grandes quantidades paralelamente com o $\mathrm{NO}^{-}$, ambos reagem produzindo o peroxidonitrito $\left(\mathrm{OONO}^{-}\right)$, altamente citotóxico (HALLIWELL; GUTERIDGE,1989).

O mecanismo bioquímico responsável pela produção de ROS pelos espermatozóides ainda não está totalmente elucidado (NICHI, 2003). Aitken (1994) sugere que a nicotinamina adenina dinucleotídeo fosfato reduzida (NADPH) seja a principal fonte de elétrons responsável pela produção de $\mathrm{O}_{2}{ }^{-}$pelo espermatozóide humano com o possível envolvimento do sistema NADPH-oxidase como ocorre em outros tipos de células.

Os espermatozóides são altamente susceptíveis aos danos causados pelas ROS. Isso ocorre devido à sua membrana plasmática possuir uma alta quantidade de ácidos graxos poliinsaturados, que são extremamente sensíveis ao ataque das ROS, e devido a baixas concentrações de enzimas antioxidantes, já que seu citoplasma é muito reduzido (NICHI, 2003; BARROS, 2007).

A produção de ROS pelos espermatozóides é um processo fisiológico normal, sendo importante para a regulação da taxa de hiperativação, para a ocorrência da reação acrossômica e para a fusão entre o espermatozóide e o oócito (SENGOKU et al., 1998; NICHI, 2003).

Embora a geração controlada de ROS tenha funções fisiológicas em diferentes tipos de células, altas concentrações delas são prejudiciais às funções celulares podendo danificar todos os tipos de biomoléculas, incluindo DNA, proteínas e lipídeos. Distúrbios no balanço oxidante-antioxidante levam ao estresse oxidativo, que, em princípio, pode ser causado por redução na quantidade de antioxidantes nos sistemas de defesa celular ou por produção elevada de ROS (HALLIWELL;GUTERIDGE,1999).

A geração de altas quantidades de ROS no sêmen está associada ao declínio do metabolismo de energia do espermatozóide, na motilidade e na viabilidade espermática e à fragmentação do DNA em cavalos, touros, carneiros, bodes e homens (NICHI, 2003). 
A produção espermática de ROS ocorre principalmente por células morfologicamente anormais e , dentre essas, especialmente as células que possuem resíduos de citoplasma (gotas proximal e distal). Acredita-se que a presença desse citoplasma residual aumentaria a capacidade dessas células imaturas de gerar NADPH, que serve como fonte de elétrons para a produção de ROS (NICHI, 2003; RODRIGUES, 2009).

Outros fatores responsáveis pela maior produção de ROS pelas células espermáticas imaturas, seria um aumento na disponibilidade de enzimas ligadas à membrana, responsáveis pela produção de ROS e, possivelmente, pela falha na elaboração de inibidores intrínsecos na atividade redutora da membrana plasmática (BARROS, 2007).

Espermatozóides imóveis e espermatozóides morfologicamente normais, porém, funcionalmente anormais, também são fontes de ROS (NICHI, 2003). Rhemrev et al. (2001), verificaram que a produção de ROS por espermatozóides imóveis, funcionalmente e/ou morfologicamente anormais ocorre, provavelmente devido à inativação dos sistemas antioxidantes dessas células.

Defini-se um antioxidante como qualquer substância que, quando presente em baixas concentrações, quando comparadas com as de um substrato oxidável, retarda ou previne significativamente a oxidação desse substrato (HALLIWELL; GUTTERIDGE,1989).

O espermatozóide conta com um sistema enzimático de defesa antioxidante, que inclui superóxido dismutase (SOD), catalase, glutationa peroxidase (GPx) e glutationa redutase (GR) , bem como os antioxidantes não enzimáticos como: ácido ascórbico e alfa-tocoferol (AITKEN,1994). No meio extracelular, ele é protegido pelo plasma seminal que contém antioxidantes, enzimáticos e não enzimáticos, como o ácido ascórbico, ácido úrico, albumina e outras proteínas, catalase, SOD, glutationa, taurina, hipotaurina e vitamina E (NICHI, 2003).

Os antioxidantes protegem a célula através da prevenção, da interceptação e do reparo das reações de oxidação (RODRIGUES, 2009).

A prevenção na formação de ROS tem como o principal meio de controle a quelação de metais de transição, que, por sua vez, ao se desprenderem dos produtos da redução do oxigênio, produzem oxidantes secundários ainda mais reativos como o radical hidroxila (BARROS, 2007). 
A interceptação das ROS está relacionada com a quebra da reação que ocorre com os radicas livres para a formação de produtos oxidantes, sendo que essa quebra deve resultar em produtos finais não radicais, ou seja, sem elétrons despareados (NICHI, 2003).

O reparo dos danos causados pelas espécies reativas ao oxigênio, no caso dos espermatozóides, se torna impossível na falta de sistemas de enzimas citoplasmáticas necessárias a essa função (BARROS, 2007; RODRIGUES, 2009).

A produção de ROS leva a ocorrência da peroxidação lipídica no espermatozóide, causando acúmulo de hidroperóxidos lipídicos na membrana espermática, que posteriormente formam o malondealdeído (MDA), permanecendo nos fluídos corporais, podendo ser usado como marcador de peroxidação lipídica. Dentre os diferentes métodos analíticos, a reação com o ácido 2-tiobarbitúrico (TBA) é o mais utilizado, em que reação do MDA com o TBA forma um composto que pode ser mensurado através de absorbância e florescência, sendo esses produtos chamados de substâncias reativas ao ácido tiobarbitúrico (TBARS) (JANERO,1990).

Zalata et al., em 1998, estudaram o efeito do estresse oxidativo induzido, através da peroxidação lipídica dos ácidos graxos que compõem os espermatozóides, e notaram que o aumento da produção de TBARS estava associado com uma diminuição significativa dos ácidos graxos poli-insaturados.

Um ano mais tarde, Zabludovky et al. (1999) verificaram que os níveis de TBARS foram significativamente maiores nas amostras que possuíam taxa de fertilização igual a zero, quando comparadas com as amostras com taxa de fertilização maior que zero.

As determinações baseiam-se na metodologia descrita por Ohkawa, Ohish e Yagi (1979), que tem como fundamento a reação de duas moléculas de ácido tiobarbitúrico (TBA) com uma molécula de malondialdeído (MDA), que só ocorre em $\mathrm{pH}$ ácido entre $90^{\circ}$ e $100^{\circ} \mathrm{C}$, mensurando após incubação a concentração de espécies reativas ao ácido tiobarbitúrico (TBARS) através da espectrofotometria, verificando a susceptibilidade do espermatozóide ao estresse oxidativo. 


\section{Material e Métodos}




\section{MATERIAL E MÉTODOS}

Foram utilizados 12 bodes adultos, com idades entre 1 e 7 anos, da raça Saanen, localizados na região de Poços de Caldas-MG. Estes animais são criados em regime de semiconfinamento em baias de $4 \mathrm{~m}^{2}$ com pé direito de $2 \mathrm{~m}$, em estação reprodutiva. Foram colhidos 2 ejaculados de cada reprodutor pelo método de vagina artificial, utilizando um outro reprodutor como manequim para que o bode efetue o salto e o sêmen coletado de uma forma mais natural possível, não deixando o método da coleta interferir nas caracteristicas seminais.

Cada amostra foi fracionada em 7 alíquotas de $200 \mu$ l. Cada fração foi diluída no meio (tris-gema-citrato com glicerol) para criopreservação contendo 0 (controle negativo), 1, 5 e 10 $\mathrm{UI} / \mathrm{ml}$ de glutationa peroxidase e 60, 120 e $240 \mathrm{UI} / \mathrm{ml}$ de catalase. Para avaliação dos tratamentos foram descongeladas 2 palhetas de cada tratamento. A avaliação do sêmen constitui-se de análise computadorizada de sêmen (CASA), morfologia espermática pelo metodo de câmara úmida, testes funcionais (eosina-nigrosina para membranas, fast-green/rosa bengala para acrossomo, 3-3'diaminobenzidina para atividade mitocondrial e SCSA para susceptibilidade a desnaturação de cromatina) e índice de peroxidação lipídica pela quantificação da malondialdeído por espectrofotometria.

\subsection{COLETA DO SÊMEN}

Duas semanas antes do início do experimento, os animais foram treinados e colocados em regime de coleta de sêmen diária. As coletas foram realizadas pelo método de vagina artificial e o manequim utilizado foi uma cabra com detecção de estro ou estrogenização prévia para colheita de sêmen por vagina artificial.

A vagina artificial foi preparada com água aquecida à $45^{\circ} \mathrm{C}$ dentro de mucosa de látex e com tubo de $50 \mathrm{~mL}$ descartável acoplado. Foi coletado sêmen, referente à duas montas de 
cada reprodutor, a fim de aumentar a quantidade de sêmen para a realização do Experimento I e II.

\subsection{EXPERIMENTO 1}

O experimento 1 visava verificar qual espécie reativa de oxigênio mais lesiva ao espermatozóide caprino.

\subsubsection{Processamento do sêmen}

Imediatamente após a obtenção de uma amostra, foi realizada uma análise microscópica, com a finalidade de qualificação do ejaculado quanto à presença de turbilhonamento e motilidade subjetiva maior ou igual a 70\%. Ejaculados que não obedecessem estas premissas seriam descartados.

Os ejaculados obtidos de um animal foram divididos em 4 alíquotas de $200 \mu$ l. As frações foram então submetidas à 3 mecanismos de produção de espécies reativas de oxigênio e à incubação com um subproduto da peroxidação lipídica, agente extremamente lesivo ao espermatozóide. Para a produção do ânion superóxido foi utilizado o sistema xantina-xantina oxidase. A produção do radical hidroxila foi induzida através da incubação das células espermáticas com sulfato de ferro $(4 \mathrm{mM})$ e ascorbato $(20 \mathrm{mM})$. O peróxido de hidrogênio e o malondialdeído (produto da peroxidação lipídica) foi utilizado diretamente, na concentração de $20 \mathrm{mM}$. Todas as incubações foram realizadas por 1 hota. 


\subsection{EXPERIMENTO 2}

O experimento 2, baseando-se nos resultados encontrados no experimento 1, visava verificar se o tratamento antioxidante com Catalase e Glutationa Peroxidase (GPx) protegeriam o espermatozóide caprino durante a criopreservação.

\subsubsection{Processamento do sêmen}

Imediatamente após a obtenção de uma amostra, foi realizada uma análise microscópica, com a finalidade de qualificação do ejaculado quanto à presença de turbilhonamento e motilidade subjetiva maior ou igual a $70 \%$. Ejaculados que não obedecessem estas premissas seriam descartados.

Os ejaculados obtidos de um animal foram divididos em 7 alíquotas de $200 \mu$ l. Cada fração foi diluída no meio (tris-gema-citrato com glicerol) para criopreservação contendo 0 (controle negativo), 1, 5 e $10 \mathrm{UI} / \mathrm{ml}$ de glutationa peroxidase e 60, 120 e $240 \mathrm{UI} / \mathrm{ml}$ de catalase. Após as alíquotas estarem diluídas com seus respectivos meios, foram envasadas em palhetas de $0,5 \mathrm{~mL}$ e raqueadas. As mesmas foram submetidas a uma curva de resfriamento de $-0,2^{\circ} \mathrm{C} / \mathrm{min}$ até atingirem $5^{\circ} \mathrm{C}$ em geladeira convencional. Após uma hora de incubação, as raques foram acondicionadas sobre um suporte mantido a 4 centímetros do nitrogênio líquido em caixa de isopor por $20 \mathrm{~min}$. Decorrido este tempo as palhetas foram imersas no nitrogênio e estocadas em botijão criogênico. As amostras foram descongeladas em duplicidade (para se evitar um possível efeito de palhetas), em banho-maria, com água aquecida à $37^{\circ} \mathrm{C}$ por $30^{\prime}$ ". Após as descongelação o conteúdo das palhetas foi transferido para microtubos de 2,0 mL contendo $1 \mathrm{~mL}$ de $\mathrm{PBS}$ aquecida à $37^{\circ} \mathrm{C}$.

As amostras foram centrifugadas a 800g por 5 minutos e ressuspensas em PBS para a remoção do diluidor. Este procedimento foi realizado duas vezes antes das amostras serem processadas com a finalidade de isolar possíveis substratos para oxidação, constituintes do meio para criopreservação (p.ex gema de ovo), de modo a prevenir que os resultados fossem mascarados pela peroxidação de lipídios não inerentes aos espermatozóides. 


\subsection{AVALIAÇÕES CONVENCIONAIS}

As avaliações convencionais empregadas neste trabalho foram: motilidade e vigor e morfologia espermática.

\subsubsection{Avaliação da motilidade espermática}

A motilidade foi então classificada, numa escala entre 0 e $100 \%$, segundo a proporção de espermatozóides móveis nos campos observados sob aumento de 100 vezes em microscópio convencional, sendo 0\% para nenhum espermatozóide móvel no campo e 100\% para todos os espermatozóides móveis.

\subsubsection{Avaliação do vigor espermático}

O vigor, foi avaliado quanto ao movimento progressivo dos espermatozóides numa escala de 0 a 5, na qual, 0 representa ausência de movimento e 5 representa movimentos progressivos intensos (WALTON, 1949).

\subsubsection{Avaliação da morfologia espermática}

A avaliação morfológica dos espermatozóides foi realizada pelo método de câmara úmida; uma alíquota de $5 \mu \mathrm{L}$ de cada amostra do ejaculado in natura, foram diluídos em $1995 \mu \mathrm{L}$ de solução de formaldeído-salina (diluição de 1: 400); $15 \mu \mathrm{L}$ de cada amostra já fixada foram colocados sobre lâmina e cobertos com lamínula; a avaliação foi feita através de 
microscopia diferencial de fase em aumento de 1250 vezes; 200 células foram computadas e a porcentagem de cada defeito foi aferida.

\subsection{TESTES FUNCIONAIS}

Os testes funcionais utilizados neste experimento foram a avaliação da integridade das membranas acrossomal e plasmática, avaliação da atividade citoquímica mitocondrial e avaliação da integridade da cromatina espermática.

\subsubsection{Avaliação da integridade acrossomal}

Visando monitorar os possíveis danos causados durante a congelação das amostras, a técnica da Coloração Simples de Pope (POPE; ZHANG; DRESSER, 1991) foi utilizada para a avaliação da integridade estrutural da membrana acrossomal. Para tanto, uma alíquota de cada amostra $(5 \mu \mathrm{l})$ foi adicionada ao Corante Simples de Pope $(5 \mu \mathrm{l})$, sendo a mistura incubada por 70 segundos. Após incubação, foram feitos esfregaços sobre lâminas de microscopia, os quais foram analisados em microscópio convencional sob aumento de 1000 vezes. Foram contadas 200 células por lâmina, classificadas como: Acrossomo Íntegro: região acrossomal de coloração lilás, levemente mais escura que a região pós-acrossomal; Acrossomo Não-íntegro: região acrossomal de coloração rosa, levemente mais clara que a região pós-acrossomal (Figura 1). 


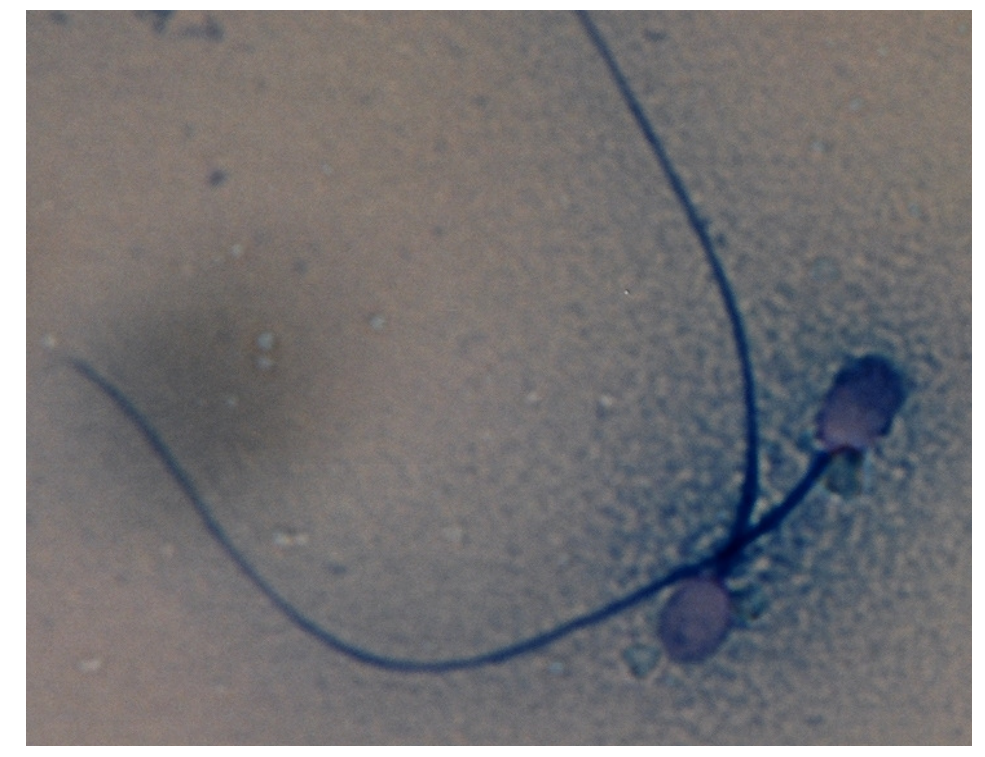

Figura 1- Espermatozóides com coloração de POPE (arquivo do L.A.)

\subsubsection{Avaliação da integridade da membrana plasmática}

Para a avaliação da integridade da membrana plasmática, foi utilizada a coloração de Eosina-Nigrosina (E/N) segundo Barth e Oko (1989). Nesta coloração, por alterações na permeabilidade das membranas dos espermatozóides, a eosina cora estas células de rosa. Os espermatozóides com membranas íntegras não permitem a entrada do corante, portanto, contrastando com o plano de fundo tomado pela coloração escura da nigrosina, as células aparecem brancas. Desta maneira, uma alíquota de sêmen $(5 \mu \mathrm{l})$ foi misturado ao corante na proporção de 1:1 e realizados esfregaços sobre lâminas de microscopia. As lâminas foram analisadas em microscópio convencional sob aumento de 1000 vezes. Foram contadas 200 células por lâmina, classificadas como células com membrana íntegra (não coradas) e não íntegra (coradas) (Figura 2). 


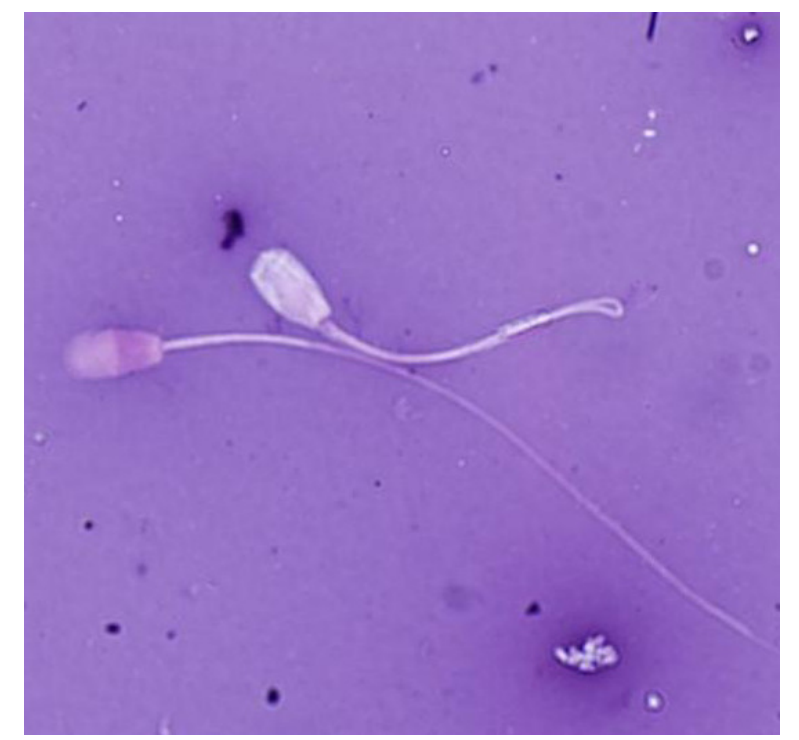

Figura 2-Espermatozóides corados com Eosina / Nigrosina (arquivo L.A.)

\subsubsection{Avaliação da atividade mitocondrial}

Segundo Hrudka (1987), a enzima Citocromo C-Oxidase (CCO) tem um papel fundamental no processo de respiração celular e metabolismo energético das células, além de ser pré-requisito para manutenção das funções osmótica e sintética, motilidade e integridade da estrutura celular. A técnica citoquímica desenvolvida por este autor baseia-se na oxidação da 3,3'-diaminobenzidina (DAB) pelo Complexo Citocromo C, o que inclui a CCO. Através de uma reação em cadeia, o DAB é polimerizado e se deposita nos locais onde ocorre a reação, ou seja, nas mitocôndrias. Esta deposição pode ser identificada através de microscopia convencional pela sua coloração marrom. Desta maneira, é possível descrever o declínio espontâneo da $\mathrm{CCO}$ ocasionado por tratamentos físicos e/ou químicos a que os espermatozóides são submetidos.

Para realização desta técnica, uma alíquota de $25 \mu \mathrm{l}$ de amostra foi incubada com $25 \mu \mathrm{L}$ de $\mathrm{DAB}(1 \mathrm{mg} / \mathrm{ml}$ de $\mathrm{PBS})$, a $37^{\circ} \mathrm{C}$, por uma hora. Após incubação, foram feitos esfregaços em lâmina de vidro e estas fixadas em formol a $10 \%$ por 10 minutos. As lâminas foram então lavadas e secas no ar sob proteção da luz.

A atividade citoquímica da mitocôndria espermática foi avaliada segundo descrito por Hrudka (1987). Desta maneira, as lâminas foram observadas em microscópio de contraste de 
fase, sob aumento de 1000 vezes, em imersão. Foram contados 200 espermatozóides/lâmina e classificados de acordo com a quantidade de corante visualizada na peça intermediária em 4 classes (Figura 3):

1 Classe I: células espermáticas com peça intermediária totalmente corada, alta atividade mitocondrial (DAB I);

2 Classe II: células espermáticas com segmentos corados (ativos) e não-corados (inativos), havendo predominância dos ativos (DAB II);

3 Classe III: células espermáticas com segmentos corados (ativos) e não-corados (inativos), havendo predominância dos inativos (DAB III);

4 Classe IV: células espermáticas com peça intermediária totalmente descorada, sem atividade mitocondrial (DAB IV).

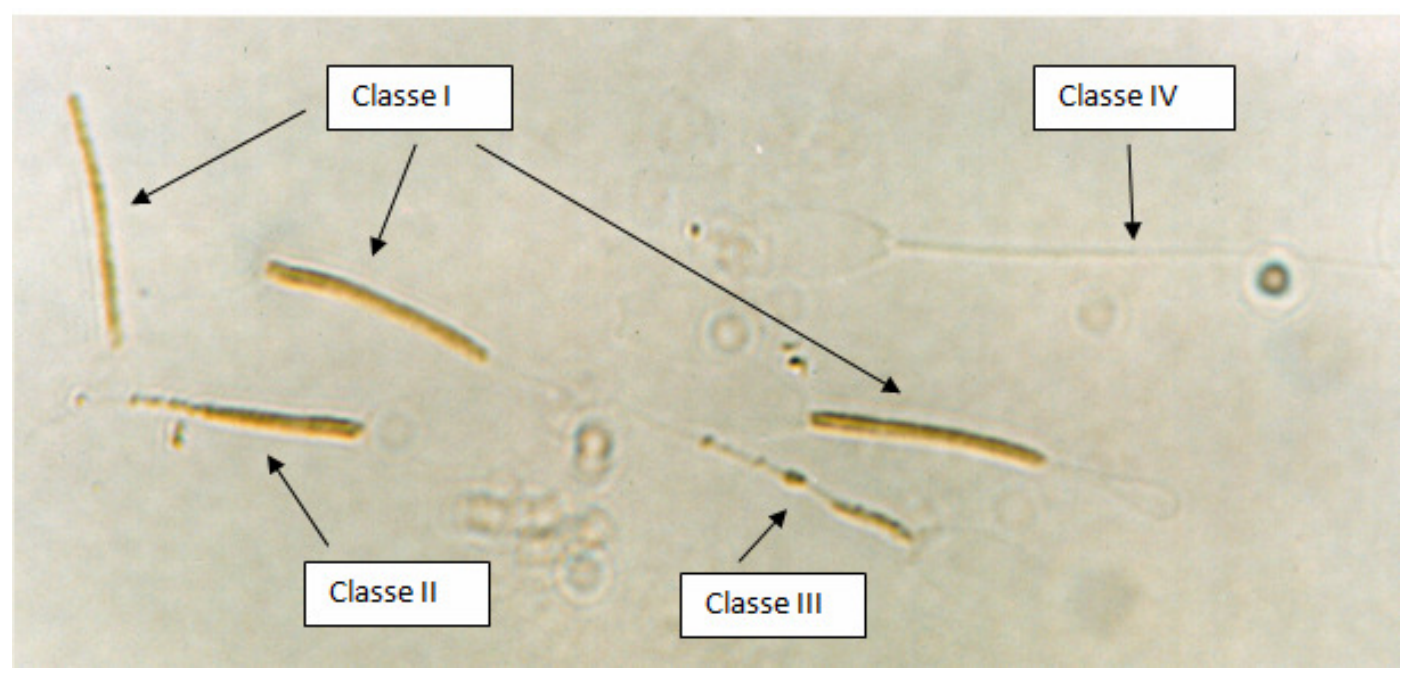

Figura 3-Grau de coloração da peça intermediária da célula espermática (Arquivo pessoal L.A.)

\subsubsection{Ensaio da estrutura da cromatina espermática (SCSA)}

Para o Teste de SCSA, foi utilizada metodologia proposta por Evenson et al. (1999). Para isso, uma palheta de sêmen de cada tratamento foi avaliada por citometria de fluxo. $\mathrm{O}$ sêmen foi descongelado em banho-maria $\left(37^{\circ} \mathrm{C} / 30\right.$ segundos $)$ e diluído em tampão TNE na concentração de $2 \times 10^{6}$ células $/ \mathrm{ml}$. Um volume de $0,1 \mathrm{ml}$ da diluição foi incubado com 0,2 $\mathrm{ml}$ de solução detergente (1\% de Triton X-100) por 30 segundos para permitir o acesso da LA 
ao DNA espermático. Após este período o sêmen foi incubado com 0,6ml de solução de LA $(6 \mu \mathrm{g} / \mathrm{ml})$. As amostras foram analisadas utilizando o citômetro de fluxo Guava EasyCyte, com excitação de $488 \mathrm{~nm}$ e $15 \mathrm{~mW}$. A avaliação da LA foi feita baseada na diferença entre a fluorescência emitida pelos espermatozóides com DNA íntegro (dupla fita), que emitem fluorescência verde e os com DNA fragmentado (fita simples), que emitem fluorescência vermelha.

\subsubsection{Avaliação da resistência ao estresse oxidativo}

A avaliação foi realizada com base na metodologia proposta por Ohkawa, Ohish e Yagi (1979), que tem como fundamento a reação de duas moléculas de ácido tiobarbitúrico com uma molécula de malondialdeído (MDA), subproduto da peroxidação de lipídeos. Foi empregado um sistema gerador de ROS com posterior mensuração da concentração de espécies reativas ao ácido tiobarbitúrico (TBARS) através da espectrofotometria, mensurando-se, portanto, a susceptibilidade das células à peroxidação lipídica.

A cada amostra descongelada, uma alíquota de $400 \mu \mathrm{l}$ da amostra, foi incubado (90 minutos $37^{\circ} \mathrm{C}$ ) com o sistema de geração de ROS, já descrito, constituído por ácido ascórbico $(20 \mathrm{mM})$ e o sulfato de ferro $(4 \mathrm{mM})$. Após o período de incubação, foram adicionados $1200 \mu \mathrm{L}$ de solução de ácido tricloroacético a $10 \%$ (TCA) e centrifugadas por 15 minutos, a $15^{\circ} \mathrm{C}$ e $5.000 \mathrm{~g}$, com a finalidade de separação de proteínas precipitadas.

Alíquotas de $1000 \mu \mathrm{L}$ de sobrenadante foram colocadas em tubos de ensaio juntamente com $1000 \mu \mathrm{L}$ de ácido tiobarbitúrico a 1\% (TBA). Os tubos contendo esta solução foram incubados em banho-maria $\left(100^{\circ} \mathrm{C}\right)$ por 15 minutos e resfriados imediatamente em banho de gelo, com a finalidade de interrupção da reação termo-dependente. A concentração de TBARS foi quantificada através de leitura em espectrofotômetro, num comprimento de onda de 532nm. Os resultados foram comparados com uma curva padrão, feita previamente, com malondialdeído. A MDA é uma das principais substâncias que reagem com o ácido tiobarbitúrico e a concentração de TBARS é determinada utilizando-se o valor 1,56 x $10^{5} \mathrm{x}$ M-1 mL-1 como coeficiente de extinção molar do malondialdeído. A concentração de TBARS nas amostras foi expressa em nanogramas de TBARS por $1 \times 10^{6}$ espermatozóides (ng/10 $\left.0^{6} \mathrm{sptz}\right)$. 


\subsection{ANÁLISE ESTATÍSTICA}

Os dados foram analisados através do programa SAS System for Windows (2000). Através do aplicativo Guided Data Analisys, os dados foram testados quanto à normalidade dos resíduos e homogeneidade das variâncias. Caso não obedecessem a estas premissas foram transformados (logarítmo na base 10 - Log10 X; Raiz quadrada - RQ X; Quadrado - X2) e se a normalidade não fosse obtida empregava-se então, o procedimento NPAR1WAY de análise de variância não paramétrica. Diferenças significantes para os dados paramétricos foram avaliadas através do teste Least Square Differences (LSD). Para descrição dos resultados, foram empregados os erros padrões das médias e as médias (média \pm erro padrão da média) dos dados originais; e os níveis de significância (p) dos dados originais, quando obedecessem às premissas: dos dados transformados, quando necessária a transformação; e dos dados analisados através da análise não paramétrica, quando não obedecessem às premissas e não houvessem transformações possíveis. A variável classificatória utilizada foi a concentração de GSH $(0,1,5$ e 10mM). As variáveis motilidade, vigor, porcentagem de células com acrossomo íntegro (ACRO), porcentagem de células com defeitos maiores (DEFMA), menores (DEFME) e totais (DEFTOT) obedeceram às premissas não sendo necessárias transformações.

As variáveis porcentagens de células DAB IV e substâncias reativas ao ácido tiobarbitúrico por espermatozóides (TBARS) obedeceram às premissas após a transformação de seus valores para o logaritmo na base 10. As variáveis porcentagens de células DAB II e III, assim como a porcentagem de espermatozóides com membrana íntegra (VIT) obedeceram às premissas após a transformação de seus valores a raiz quadrada. As variáveis resposta porcentagem de células DAB I, substâncias reativas ao ácido tiobarbitúrico por mL (MDA) e porcentagem de células com fragmentação de DNA (SCSA), obedeceram ás premissas após a transformação de seus valores para o quadrado, o inverso e o inverso da raiz quadrada, respectivamente. O nível de significância utilizado para rejeitar H0 (hipótese de nulidade) foi de $5 \%$, isto é, para um nível de significância menor que 0,05 , considerou-se que ocorreram diferenças estatísticas entre as variáveis classificatórias (concentrações de GSH) para uma determinada variável resposta. Por serem todas paramétricas, as variáveis foram analisadas 
através da correlação de Pearson, sendo os resultados expressos através do coeficiente de correlação (r) e seu nível de significância (p). 
$\underline{\text { Resultados e Discussão }}$ 


\section{RESULTADOS E DISCUSSÃO}

Os resultados do presente estudo apresentados separadamente, de acordo com a metodologia apresentada.

\subsection{INDUÇÃO DO ESTRESSE OXIDATIVO}

Os resultados referentes ao efeito dos diferentes mecanismos indução do estresse oxidativo de serão apresentados nas tabelas 1, 2, 3 e 4 e na figura 4. 
Tabela 1- Efeitos das induções com diferentes espécies reativas de oxigênio e do subroduto da peroxidação lipídica (Ânion: ânion superóxido; $\mathrm{H}_{2} \mathrm{O}_{2}$ : peróxido de hidrogênio; Hidroxila: radical hidroxila; MDA: malondialdeído) nas alterações morfológicas em sêmen de caprinos. Poços de Caldas, MG

\begin{tabular}{|c|c|c|c|c|}
\hline & Anion & $\overline{\mathrm{H}} \mathrm{H}_{2} \mathrm{O}_{2}$ & Hidroxila & $\overline{\mathrm{MDA}}$ \\
\hline Estreita na base & $0,25 \pm 025$ & $0,08 \pm 0,08$ & $0,08 \pm 0,08$ & $0,25 \pm 0,13$ \\
\hline Piriforme & 0 & 0 & 0 & 0 \\
\hline Contorno & $0,08 \pm 0,08$ & $0,75 \pm 0,53$ & $0,50 \pm 0,23$ & $0,50 \pm 0,50$ \\
\hline Subdesenvolvida & $0,08 \pm 0,08$ & $0,08 \pm 0,08$ & 0 & 0 \\
\hline Acrossomo & 0 & $0,16 \pm 0,16$ & 0 & 0 \\
\hline Superficie Anormal & $0^{\mathrm{b}}$ & $0^{\mathrm{b}}$ & $0^{\mathrm{b}}$ & $0,33 \pm 0,19^{\mathrm{a}}$ \\
\hline Peça Intermediária & $0^{\mathrm{b}}$ & $0^{\mathrm{b}}$ & $0,17 \pm 0,11^{\mathrm{a}}$ & $0^{\mathrm{b}}$ \\
\hline Cauda Dobrada c/Gota & $0,25 \pm 0,18^{\mathrm{b}}$ & $0,66 \pm 0,39^{\mathrm{ab}}$ & $1,33 \pm 0,37^{\mathrm{a}}$ & $0,25 \pm 0,13^{b}$ \\
\hline Cauda Forte Enrrolada & $2,42 \pm 1,03$ & $1,08 \pm 0,48$ & $1,33 \pm 0,50$ & $1,42 \pm 0,64$ \\
\hline Cauda Forte Dobrada & $3,25 \pm 1,17$ & $3,00 \pm 0,74$ & $1,75 \pm 0,44$ & $4,00 \pm 1,34$ \\
\hline Fratura de Cauda & $0,08 \pm 0,08$ & $0,08 \pm 0,08$ & 0 & $0,17 \pm 0,17$ \\
\hline Cabeça Destacada & 0 & 0 & $0,08 \pm 0,08$ & $0,08 \pm 0,08$ \\
\hline Cauda Destacada & $0,17 \pm 0,11^{\mathrm{a}}$ & $0^{\mathrm{b}}$ & $0^{\mathrm{b}}$ & $0^{\mathrm{b}}$ \\
\hline Gota Proximal & $0,58 \pm 0,26$ & $0,33 \pm 0,26$ & $0,33 \pm 0,14$ & $0,08 \pm 0,08$ \\
\hline Cabeça Estreita & $0,25 \pm 0,25$ & $0,42 \pm 0,34$ & $0,17 \pm 0,17$ & $0,33 \pm 0,26$ \\
\hline Cabeça Gigante & 0 & 0 & 0 & 0 \\
\hline Abaxial & 0 & 0 & 0 & 0 \\
\hline Cabeça Pequena Normal & $0,08 \pm 0,08$ & $0,25 \pm 0,18$ & 0 & 0 \\
\hline Cabeça Solta Normal & $0,67 \pm 0,31$ & $1,00 \pm 0,39$ & $0,67 \pm 0,43$ & $0,92 \pm 0,47$ \\
\hline Retro Axial & $0,08 \pm 0,08$ & 0 & $0,17 \pm 0,11$ & 0 \\
\hline Cauda Enrrolada & $3,50 \pm 1,14$ & $3,08 \pm 0,77$ & $2,33 \pm 0,57$ & $2,50 \pm 0,83$ \\
\hline Cauda Dobrada & $4,17 \pm 0,68$ & $2,33 \pm 0,74$ & $3,17 \pm 0,89$ & $2,83 \pm 0,80$ \\
\hline Gota Distal & $1,91 \pm 0,80$ & $2,17 \pm 1,21$ & $1,25 \pm 0,35$ & $1,17 \pm 0,67$ \\
\hline
\end{tabular}

a,b,c: letras diferentes indicam diferença estatística $(\mathrm{p}<0,05)$ 
Tabela 2- Efeitos das induções com diferentes espécies reativas de oxigênio e do subproduto da peroxidação lipídica (Ânion: ânion superóxido; $\mathrm{H}_{2} \mathrm{O}_{2}$ : peróxido de hidrogênio; Hidroxila: radical hidroxila; MDA: malondialdeído) nas taxas de anormalidades morfológicas espermáticas maiores e menores em sêmen de caprinos. Poços de Caldas, MG

\begin{tabular}{lcccc} 
& Anion & $\mathrm{H}_{2} \mathrm{O}_{2}$ & Hidroxila & MDA \\
\hline Defeitos Maiores (\%) & $7,17 \pm 1,98$ & $6,25 \pm 1,66$ & $5,58 \pm 1,20$ & $7,08 \pm 1,82$ \\
Defeitos Menores (\%) & $10,67 \pm 1,59$ & $9,25 \pm 2,46$ & $7,75 \pm 1,26$ & $7,75 \pm 1,40$
\end{tabular}

a,b,c: letras diferentes indicam diferença estatística $(\mathrm{p}<0,05)$

Tabela 3- Efeitos das induções com diferentes espécies reativas de oxigênio e do subproduto da peroxidação lipídica (Ânion: ânion superóxido; $\mathrm{H}_{2} \mathrm{O}_{2}$ : peróxido de hidrogênio; Hidroxila: radical hidroxila; MDA: malondialdeído) nas taxas de espermatozóides com membrana e acrossomo íntegros, espermatozóides com atívidade mitocondrial DAB I, DAB II, DAB III e DAB IV, e susceptibilidade ao estresse oxidativo (TBARS) em sêmen de caprinos. Poços de Caldas, MG

\begin{tabular}{cccc}
\hline \hline Anion & $\mathrm{H}_{2} \mathrm{O}_{2}$ & Hidroxila & MDA
\end{tabular}

\begin{tabular}{lcccc}
\hline M. Plasmática (\%) & $65,97 \pm 3,68^{\mathrm{a}}$ & $48,80 \pm 7,69^{\mathrm{b}}$ & $67,06 \pm 3,79^{\mathrm{a}}$ & $64,19 \pm 4,71^{\mathrm{a}}$ \\
Acrossomo (\%) & $75,90 \pm 4,78$ & $70,60 \pm 6,49$ & $78,94 \pm 4,59$ & $79,19 \pm 4,25$ \\
DAB I (\%) & $59,84 \pm 4,64$ & $55,20 \pm 8,27$ & $60,31 \pm 4,69$ & $58,73 \pm 4,89$ \\
DAB II (\%) & $12,50 \pm 3,24^{\mathrm{ab}}$ & $3,83 \pm 1,83^{\mathrm{c}}$ & $5,28 \pm 1,75^{\mathrm{bc}}$ & $13,41 \pm 3,36^{\mathrm{a}}$ \\
DAB III (\%) & $6,87 \pm 1,69$ & $3,67 \pm 0,91$ & $3,25 \pm 1,24$ & $6,84 \pm 1,84$ \\
DAB IV (\%) & $20,87 \pm 4,28^{\mathrm{ab}}$ & $37,30 \pm 8,77^{\mathrm{a}}$ & $31,25 \pm 5,09^{\mathrm{ab}}$ & $18,87 \pm 4,60^{\mathrm{b}}$ \\
TBARS (ng/10 & $998,32 \pm 245,65^{\mathrm{b}}$ & $759,60 \pm 151,73^{\mathrm{b}}$ & $2178,0 \pm 358,78^{\mathrm{a}}$ & $765,4 \pm 204,3^{\mathrm{b}}$ \\
espermatozóides) & & & &
\end{tabular}

a,b,c: letras diferentes indicam diferença estatística $(\mathrm{p}<0,05)$ 


\begin{tabular}{|c|c|c|c|c|c|c|c|}
\hline & Memb. & Acro. & DAB I & DAB II & DAB III & DAB IV & $\begin{array}{c}\text { TBARS } \\
\left(\mathrm{ng} / 10^{6}\right. \\
\text { sptz) }\end{array}$ \\
\hline Memb. & $\begin{array}{l}1.00 \\
(0.0)\end{array}$ & $\begin{array}{c}0.33 \\
(0.007)\end{array}$ & $\begin{array}{c}0.41 \\
(0.0008)\end{array}$ & $\begin{array}{c}0.22 \\
(0.0002)\end{array}$ & $\begin{array}{c}0.09 \\
(0.47)\end{array}$ & $\begin{array}{c}-0.50 \\
(<0.0001)\end{array}$ & $\begin{array}{l}-0.15 \\
(0.23)\end{array}$ \\
\hline Acro. & $\begin{array}{c}0.33 \\
(0.007)\end{array}$ & $\begin{array}{l}1.00 \\
(0.0)\end{array}$ & $\begin{array}{c}0.33 \\
(0.007)\end{array}$ & $\begin{array}{l}0.02 \\
(0.85)\end{array}$ & $\begin{array}{l}-0.16 \\
(0.18)\end{array}$ & $\begin{array}{l}-0.17 \\
(0.17)\end{array}$ & $\begin{array}{c}0.06 \\
(0.59)\end{array}$ \\
\hline DAB I & . & $\begin{array}{c}0.33 \\
(0.0075)\end{array}$ & $\begin{array}{c}1.00 \\
(0.00)\end{array}$ & $\begin{array}{l}-0.08 \\
(0.53)\end{array}$ & $\begin{array}{l}-0.27 \\
(0.02)\end{array}$ & $\begin{array}{c}-0.59 \\
(<0.0001)\end{array}$ & $\begin{array}{l}-0.15 \\
(0.24)\end{array}$ \\
\hline DAB II & . & . & $\begin{array}{l}-0.08 \\
(0.53)\end{array}$ & $\begin{array}{c}1.0 \\
(0.0)\end{array}$ & $\begin{array}{c}0.61 \\
(<0.0001)\end{array}$ & $\begin{array}{c}-0.59 \\
(<0.0001)\end{array}$ & $\begin{array}{c}-0.31 \\
(0.01)\end{array}$ \\
\hline DAB III & . & . & . & $\begin{array}{c}0.61 \\
(<0.0001 \\
)\end{array}$ & $\begin{array}{l}1.00 \\
(0.0)\end{array}$ & $\begin{array}{l}-0.35 \\
(0.00)\end{array}$ & $\begin{array}{l}-0.35 \\
(0.00)\end{array}$ \\
\hline DAB IV & . & . & . & . & $\begin{array}{l}-0.35 \\
(0.0)\end{array}$ & $\begin{array}{c}1.0 \\
(0.0)\end{array}$ & $\begin{array}{c}0.36 \\
(0.00)\end{array}$ \\
\hline $\begin{array}{l}\text { TBARS } \\
\left(\mathrm{ng} / 10^{6}\right. \\
\text { sptz) }\end{array}$ & . & . & . & . & . & . & $\begin{array}{l}1.0 \\
(0.0)\end{array}$ \\
\hline
\end{tabular}

Figura 4- Correlação entre as taxas de espermatozóides com membrana e acrossomo íntegros, espermatozóides com atívidade mitocondrial DAB I, DAB II, DAB III e DAB IV, e susceptibilidade ao estresse oxidativo (TBARS) em sêmen de caprinos submetido à indução do estresse oxidativo com diferentes espécies reativas de oxigênio. Poços de Caldas, MG.

As diferenças encontradas em algumas anormalidades espermaticas frente às diferentes espécies reativas de oxigênio ocorreram apenas naqueles defeitos com baixa prevalência (Tabela 1). Além disto, alterações como a cauda dobrada com gota, têm sua origem no testículo, ou seja, antes que qualquer efeito advindo da manipulação do sêmen possa ser observado. Assim, muito provavelmente, tais diferenças ocorreram por artefato de técnica, o que pode ser comprovado pela ausência de diferenças estatísticas entre as induções 
nos defeitos quando considerados conjuntamente (defeitos menores e maiores; Tabela 2). De fato, apesar da importância de espermatozóide a morfologicamente normais para que uma amostra espermática seja viável, estudos indicam que mesmo espermatozóides normais podem apresentar anormalidades funcionais que inviabilizariam a fecundação (AITIKEN et al., 2004).

$\mathrm{Na}$ avaliação das características funcionais dos espermatozóides submetidos à indução do estresse oxidativo verificou-se que o peroxido de hidrogênio $\left(\mathrm{H}_{2} \mathrm{O}_{2}\right)$ foi o mais deletério. Uma menor porcentagem de espermatozóides com membrana íntegra foi observada nas amostras incubadas com o peróxido de hidrogênio $\left(\mathrm{H}_{2} \mathrm{O}_{2}\right)$ em comparação às amostras tratados com ânion superóxido, radical hidroxila e malondialdeído $(48,80 \pm$ 7,69\%, 65,97 \pm 3,68, 67,06 $\pm 3,79$ e 64,19 \pm 4,71, respectivamente; Tabela 3). Da mesma forma, maiores taxas de espermatozóides com nenhuma atividade mitocondrial foram observadas no grupo tratado com peróxido de hidrogênio em comparação ao tratado com MDA $(37,30 \pm 8,77$ e 18,87 \pm 4,60, respectivamente; Tabela 3). Apesar destes resultados, a espécie reativa de oxigênio que mais induziu a peroxidação lipídica foi o radical hidroxila (Radical: 2178,0 $\pm 358,78$; Ânion: 998,32 \pm 245,65; $\mathbf{H}_{2} \mathbf{O}_{2}$ : 759,60 \pm 151,73; MDA: 765,4 $\pm 204,3$; Tabela 3). No entanto, é importante salientar que os níveis de produção de espécies reativas de oxigênio utilizados neste desafio são níves extremamente altos, dificilmente encontrados em sistemas biológicos. No entanto, é importante destacar que, mesmo não sendo tão lesivo ao espermatozoide caprino, como verificado com os testes funcionais, o efeito do radical hidroxila não pode ser ignorado visto que a peroxidação dos colesterois libera subprodutos que com propriedades mutagênicas e que com potencial de causar danos de DNA (BLAIR, 2001).

Verificou-se que a maior susceptibilidade dos espermatozóides caprinos submetidos ao estresse oxidativo correlacionou positivamente com uma atividade mitocondrial prejudicada (TBARS e DAB IV; $r=0,33, p=0,001$; Tabela 4), o que indica que células mais suscetíveis ao estresse oxidativo apresentavam uma menor atividade mitocondrial. Além disto, verificou-se uma alta correlação negativa entre espermatozóides com membrana íntegra e células sem mitocondrias ativas (Membrana e DAB IV; $r=-0,50, p<0,0001$ ), indicando que quanto mais células com mitocôndria sem atividade maior a porcentagem de células com a membrana lesada. Uma hipótese para explicar estes resultados seria que a indução das espécies reativas de oxigênio poderia levar a danos de membrana e mitocôndria que, por sua 
vez, levaram à liberação de mais fatores pró-oxidativos, exacerbando os efeitos do estresse oxidativo (CURI, et al.,2003) (Figura5).

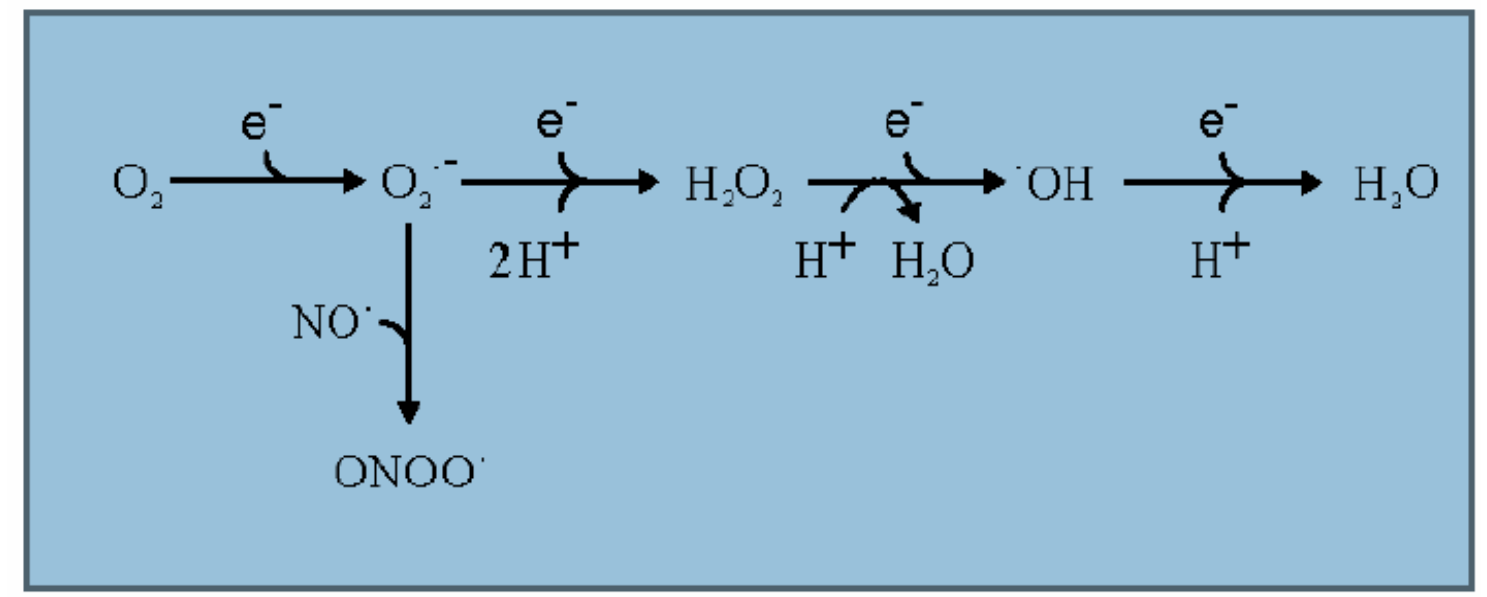

Figura 5- Formulação das espécies reativas de oxigênio (EROs), modificado de Chabot et al., (1998).

\subsection{EFEITO DO TRATAMENTO COM CATALASE}

Os resultados referentes ao tratamento com a enzima antioxidante catalase serão apresentados nas tabelas 5, 6, 7 e 8 . 
Tabela 4- Efeitos do tratamento de amostras espermáticas caprinas criopreservadas com diferentes concentrações de catalase $(0,60,120$ e $240 \mathrm{UI} / \mathrm{mL})$ nas taxas de anormalidades espermáticas. Poços de Caldas, MG

\begin{tabular}{|c|c|c|c|c|}
\hline & & & & \\
\hline & Controle & Cat-60 & Cat-120 & Cat-240 \\
\hline Estreita na base & $0,33 \pm 0,21$ & 0 & 0 & $0,67 \pm 0,49$ \\
\hline Piriforme & 0 & 0 & 0 & 0 \\
\hline Contorno & $0,33 \pm 0,33$ & $0,17 \pm 0,17$ & 0 & $0,17 \pm 0,17$ \\
\hline Subdesenvolvida & 0 & 0 & 0 & $0,17 \pm 0,17$ \\
\hline Acrossomo & 0 & 0 & $0,33 \pm 0,33$ & 0 \\
\hline Superficie Anormal & 0 & $0,17 \pm 0,17$ & 0 & $0,33 \pm 0,33$ \\
\hline Peça Intermediária & 0 & 0 & 0 & 0 \\
\hline Cauda Dobrada c/Gota & $0,67 \pm 0,33$ & $0,67 \pm 0,49$ & $0,50 \pm 0,34$ & $0,83 \pm 0,65$ \\
\hline Cauda Forte Enrrolada & $1,83 \pm 0,87$ & $1,50 \pm 0,85$ & $2,67 \pm 1,46$ & $1,50 \pm 0,85$ \\
\hline Cauda Forte Dobrada & $5,17 \pm 2,21$ & $2,0 \pm 0,68$ & $4,17 \pm 2,44$ & $4,50 \pm 1,69$ \\
\hline Fratura de Cauda & 0 & 0 & 0 & $0,33 \pm 0,33$ \\
\hline Cabeça Destacada & 0 & 0 & $0,17 \pm 0,17$ & $0,17 \pm 0,17$ \\
\hline Cauda Destacada & 0 & 0 & $0,17 \pm 0,17$ & 0 \\
\hline Gota Proximal & $0,50 \pm 0,50$ & $0,17 \pm 0,17$ & $0,83 \pm 0,48$ & $0,33 \pm 0,21$ \\
\hline Cabeça Estreita & $0,50 \pm 0,50$ & $0,50 \pm 0,50$ & 0 & $0,17 \pm 0,17$ \\
\hline Cabeça Gigante & 0 & 0 & 0 & 0 \\
\hline Abaxial & 0 & 0 & 0 & 0 \\
\hline $\begin{array}{l}\text { Cabeça Pequena } \\
\text { Normal }\end{array}$ & 0 & $0,17 \pm 0,17$ & $0,33 \pm 0,33$ & 0 \\
\hline Cabeça Solta Normal & $0,83 \pm 0,83$ & $1,33 \pm 0,67$ & $0,50 \pm 0,34$ & $0,67 \pm 0,33$ \\
\hline Retro Axial & 0 & $0,17 \pm 0,17$ & 0 & $0,17 \pm 0,17$ \\
\hline Cauda Enrrolada & $1,67 \pm 0,49$ & $3,33 \pm 0,95$ & $3,33 \pm 1,67$ & $3,67 \pm 1,65$ \\
\hline Cauda Dobrada & $3,50 \pm 0,76$ & $4,17 \pm 1,47$ & $3,17 \pm 1,27$ & $2,83 \pm 1,56$ \\
\hline Gota Distal & $1,83 \pm 1,47$ & $3,33 \pm 2,39$ & $1,67 \pm 0,92$ & $1,17 \pm 0,54$ \\
\hline
\end{tabular}


Tabela 5- Efeitos do tratamento de amostras espermáticas caprinas criopreservadas com diferentes concentrações de catalase $(0,60,120$ e $240 \mathrm{UI} / \mathrm{mL})$ nas taxas de anormalidades morfológicas espermáticas maiores e menores

\begin{tabular}{llll}
\hline \hline Contrôle & Cat-60 & Cat-120 & Cat-240
\end{tabular}

\begin{tabular}{lllll}
\hline Defeitos Maiores(\%) & $8,83 \pm 3,14$ & $4,67 \pm 0,99$ & $8,83 \pm 3.39$ & $9,0 \pm 2,54$ \\
Defeitos Menores(\%) & $8,33 \pm 1,76$ & $13.0 \pm 4,42$ & $9,0 \pm 2,08$ & $8,67 \pm 2,31$
\end{tabular}

a,b,c: letras diferentes indicam diferença estatística $(\mathrm{p}<0,05)$

Tabela 6- Efeitos do tratamento de amostras espermáticas caprinas criopreservadas com diferentes concentrações de catalase $(0,60,120$ e $240 \mathrm{UI} / \mathrm{mL})$ nas taxas de espermatozóides com membrana e acrossomo íntegros, espermatozóides com atívidade mitocondrial DAB I, DAB II, DAB III e DAB IV, e susceptibilidade ao estresse oxidativo (TBARS). Poços de Caldas, MG

$\begin{array}{llll}\text { Contrôle } & \text { Cat-60 } & \text { Cat-120 } & \text { Cat-240 }\end{array}$

\begin{tabular}{lcccc}
\hline M. Plasmática(\%) & $25,08 \pm 4,80^{\mathrm{a}}$ & $16,25 \pm 3,76^{\mathrm{ab}}$ & $15,50 \pm 2,60^{\mathrm{ab}}$ & $13,42 \pm 2,96^{\mathrm{b}}$ \\
SCSA(\%) & $3,53 \pm 0,82$ & $3,67 \pm 0,37$ & $4,58 \pm 1,01$ & $4,56 \pm 0,73$ \\
Acrossomo(\%) & $45,33 \pm 6,75$ & $41,75 \pm 6,92$ & $43,92 \pm 6,83$ & $44,08 \pm 8,87$ \\
DAB I (\%) & $44,0 \pm 5,18$ & $48,83 \pm 5,75$ & $43,28 \pm 5,82$ & $39,60 \pm 4,12$ \\
DAB II(\%) & $26,33 \pm 2,99$ & $23,25 \pm 4,95$ & $27,86 \pm 4,33$ & $33,20 \pm 1,32$ \\
DAB III(\%) & $10,17 \pm 2,76$ & $10,50 \pm 2,50$ & $11,86 \pm 2,90$ & $12,40 \pm 3,51$ \\
DAB IV(\%) & $19,50 \pm 2,86$ & $17,42 \pm 3,62$ & $16,0 \pm 3,66$ & $14,80 \pm 2,04$ \\
TBARS (ng/10 & $625,67 \pm 169,54$ & $652,76 \pm 189,92$ & $660,38 \pm 182,99$ & $442,23 \pm 92,75$ \\
sptz) & & & &
\end{tabular}

a,b,c: letras diferentes indicam diferença estatística $(\mathrm{p}<0,05)$ 


\begin{tabular}{|c|c|c|c|c|c|c|c|c|}
\hline & $\begin{array}{c}\text { Memb } \\
.\end{array}$ & SCSA & $\begin{array}{c}\text { TBARS } \\
\left(\mathrm{ng} / 10^{6}\right. \\
\text { sptz) }\end{array}$ & ACRO & DAB I & DAB II & DAB III & DAB IV \\
\hline Memb. & $\begin{array}{l}1.00 \\
(0.0)\end{array}$ & $\begin{array}{l}-0.19 \\
(0.46)\end{array}$ & $\begin{array}{l}-0.43 \\
(0.07)\end{array}$ & $\begin{array}{c}0.61 \\
(0.007)\end{array}$ & $\begin{array}{c}0.31 \\
(0.22)\end{array}$ & $\begin{array}{l}-0.49 \\
(0.04)\end{array}$ & $\begin{array}{l}-0.56 \\
(0.01)\end{array}$ & $\begin{array}{l}0.35 \\
(0.16)\end{array}$ \\
\hline SCSA & & $\begin{array}{l}1.00 \\
(0.0)\end{array}$ & $\begin{array}{l}0.37 \\
(0.13)\end{array}$ & $\begin{array}{l}-0.02 \\
(0.92)\end{array}$ & $\begin{array}{l}0.06 \\
(0.82)\end{array}$ & $\begin{array}{l}0.07 \\
(0.79)\end{array}$ & $\begin{array}{c}0.13 \\
(0.61)\end{array}$ & $\begin{array}{l}-0.13 \\
(0.61)\end{array}$ \\
\hline $\begin{array}{l}\text { TBARS } \\
\left(\mathrm{ng} / 10^{6}\right. \\
\text { sptz) }\end{array}$ & . & . & $\begin{array}{l}1.0 \\
(0.0)\end{array}$ & $\begin{array}{l}-0.69 \\
(0.001)\end{array}$ & $\begin{array}{l}0.07 \\
(0.78)\end{array}$ & $\begin{array}{l}-0.32 \\
(0.20)\end{array}$ & $\begin{array}{l}0.50 \\
(0.04)\end{array}$ & $\begin{array}{l}-0.34 \\
(0.19)\end{array}$ \\
\hline ACRO & & & & $\begin{array}{l}1.00 \\
(0.0)\end{array}$ & $\begin{array}{l}0.22 \\
(0.40)\end{array}$ & $\begin{array}{l}-0.03 \\
(0.90)\end{array}$ & $\begin{array}{c}-0.73 \\
(0.0009)\end{array}$ & $\begin{array}{c}0.37 \\
(0.14)\end{array}$ \\
\hline DAB I & & & $\cdot$ & & $\begin{array}{l}1.0 \\
(0.0)\end{array}$ & $\begin{array}{l}-0.55 \\
(0.02)\end{array}$ & $\begin{array}{l}-0.49 \\
(0.04)\end{array}$ & $\begin{array}{l}-0.58 \\
(0.01)\end{array}$ \\
\hline DAB II & & & . & • & & $\begin{array}{l}1.0 \\
(0.0)\end{array}$ & $\begin{array}{c}-0.008 \\
(0.97)\end{array}$ & $\begin{array}{c}0.07 \\
\left(0.78_{-}\right.\end{array}$ \\
\hline DAB III & & & . & . & • & & $\begin{array}{l}1.0 \\
(0.0)\end{array}$ & $\begin{array}{l}-0.11 \\
(0.67)\end{array}$ \\
\hline DAB IV & & & & & & & & $\begin{array}{c}1.0 \\
(0.0)\end{array}$ \\
\hline
\end{tabular}

Figura 6- Correlação entre as taxas de espermatozóides com membrana e acrossomo íntegros, espermatozóides com atívidade mitocondrial DAB I, DAB II, DAB III e DAB IV, e susceptibilidade ao estresse oxidativo (TBARS) em sêmen criopreservado de caprinos suplementado com diferentes concentrações de catalase. Poços de Caldas, MG.

Baseado nos resultados do experimento 1, esperava-se que o tratamento do diluidor com catalase, importante antioxidante responsável pela destruição do peróxido de hidrogênio $\left(\mathrm{H}_{2} \mathrm{O}_{2}\right)$, levasse a uma melhora na qualidade espermática pós descongelamento so sêmen de bodes. No entanto, a catalase não apresentou efeitos benéficos ao sêmen criopreservado de bodes em relação às alterações morfológicas (Tabelas 5 e 6) ou aos testes funcionais (Tabela 
7). De fato, em relação à integridade de membrana plasmática, o tratamento com catalase apresentou efeitos deletérios, sendo que o tratamento com $240 \mathrm{UI} / \mathrm{mL}$ apresentou uma porcentagem menor de espermatozóides com membrana íntegra quando comparado com as amostras controle $(13,42 \pm 2,96$ e 25,08 \pm 4,80, respectivamente; Tabela 7).

Os níveis de catalase observados no sêmen de diferentes espécies variam extremamente. Estudos em touros (NICHI et al., 2006), cachaços (FOOTE, 1962) e cães (STRZEZEK et al., 2009) não observaram níveis detectáveis de catalase no plasma seminal. Por outro lado, estudos anteriores verificaram altos níveis de catalase no sêmen de coelhos (FOOTE, 2000) e garanhões (BALL et al., 2000). Apesar da possível influência da sensibilidade das diferentes técnicas utilizadas, presume-se que, nas espécies em que a catalase não foi detectada, os níveis, se presentes, seriam relativamente baixos. Assim, uma hipótese para explicar o efeito deletério da catalase encontrados no presente estudo, seria que os espermatozóides de espécies com baixos níveis poderiam ser sensíveis ao tratamento com esta enzima. No entanto, estudos visando avaliar os níveis de catalase em caprinos são necessários.

Além destes resultados, verificou-se que as amostras tratadas com catalase e que continham espermatozóides mais susceptiveis ao estresse oxidativo apresentavam uma menor porcentlagem de células com acrossomo íntegro ( $\mathrm{r}=-0,69, \mathrm{p}=0,001)$, uma tendência a uma menor porcentagem de células com membrana íntegra $(\mathrm{r}=-0,43, \mathrm{p}=0,07)$ e uma maior porcentagem de células com mitocondria severamente alterada (DAB III; $r=0,50, p=0,04$; Tabela 8), evidenciando a baixa eficiência da catalase na contenção dos danos oxidativos provocados pela criopreservação do sêmen de caprinos.

\subsection{EFEITO DO TRATAMENTO COM GLUTATIONA PEROXIDASE}

Os resultados referentes ao tratamento com a enzima antioxidante glutationa peroxidase serão apresentados nas tabelas 9, 10, 11 e 12 . 
Tabela 7- Efeitos do tratamento de amostras espermáticas caprinas criopreservadas com diferentes concentrações de glutationa peroxidase $(0,1,5$ e $10 \mathrm{UI} / \mathrm{mL})$ nas taxas de anormalidades espermáticas. Poços de Caldas, MG

\begin{tabular}{|c|c|c|c|c|}
\hline & Controle & GPXt-01 & GPX-05 & GPX-10 \\
\hline Estreita na base & $0,33 \pm 0,21$ & 0 & $0,33 \pm 0,21$ & 0 \\
\hline Piriforme & 0 & 0 & 0 & 0 \\
\hline Contorno & $0,33 \pm 0,33$ & $0,33 \pm 0,33$ & $1,17 \pm 0,98$ & $1,50 \pm 1,02$ \\
\hline Subdesenvolvida & 0 & 0 & $0,17 \pm 0,17$ & 0 \\
\hline Acrossomo & 0 & 0 & 0 & 0 \\
\hline Superficie Anormal & 0 & 0 & 0 & 0 \\
\hline Peça Intermediária & 0 & 0 & $0,17 \pm 0,17$ & 0 \\
\hline Cauda Dobrada c/Gota & $0,67 \pm 0,33^{\mathrm{ab}}$ & $0,17 \pm 0,17^{\mathrm{b}}$ & $1,50 \pm 0,72^{a}$ & $0,50 \pm 0,22^{\mathrm{ab}}$ \\
\hline Cauda Forte Enrrolada & $1,83 \pm 0,87$ & $2,83 \pm 1,72$ & $1,50 \pm 0,67$ & $0,67 \pm 0,49$ \\
\hline Cauda Forte Dobrada & $5,17 \pm 2,21$ & $2,0 \pm 0,52$ & $3,17 \pm 0,48$ & $1,83 \pm 0,70$ \\
\hline Fratura de Cauda & 0 & 0 & $0,17 \pm 0,17$ & $0,17 \pm 0,17$ \\
\hline Cabeça Destacada & 0 & 0 & 0 & 0 \\
\hline Cauda Destacada & 0 & 0 & 0 & 0 \\
\hline Gota Proximal & $0,50 \pm 0,50$ & $0,33 \pm 0,33$ & $0,17 \pm 0,17$ & $0,33 \pm 0,21$ \\
\hline Cabeça Estreita & $0,50 \pm 0,50$ & 0 & $0,33 \pm 0,33$ & $1,17 \pm 0,65$ \\
\hline Cabeça Gigante & 0 & 0 & 0 & 0 \\
\hline Abaxial & 0 & 0 & 0 & 0 \\
\hline $\begin{array}{l}\text { Cabeça Pequena } \\
\text { Normal }\end{array}$ & 0 & 0 & 0 & $0,17 \pm 0,17$ \\
\hline Cabeça Solta Normal & $0,83 \pm 0,83$ & $0,83 \pm 0,54$ & $1,50 \pm 0,85$ & $2,17 \pm 1,45$ \\
\hline Retro Axial & 0 & 0 & $0,17 \pm 0,17$ & 0 \\
\hline Cauda Enrolada & $1,67 \pm 0,49$ & $2,50 \pm 1,43$ & $2,83 \pm 0,87$ & $2,17 \pm 0,40$ \\
\hline Cauda Dobrada & $3,50 \pm 0,76$ & $3,33 \pm 1,56$ & $2,67 \pm 0,99$ & $2,67 \pm 0,80$ \\
\hline Gota Distal & $1,83 \pm 1,47$ & $0,83 \pm 0,65$ & $1,50 \pm 0,76$ & $1,67 \pm 0,99$ \\
\hline
\end{tabular}


Tabela 8- Efeitos do tratamento de amostras espermáticas caprinas criopreservadas com diferentes concentrações de glutationa peroxidase $(0,1,5$ e $10 \mathrm{UI} / \mathrm{mL})$ nas taxas de anormalidades morfológicas espermáticas maiores e menores

\begin{tabular}{lcccc} 
& Controle & GPX-01 & GPX-05 & GPX-10 \\
\hline Defeitos Maiores(\%) & $8,83 \pm 3,14$ & $5,67 \pm 2,30$ & $8,33 \pm 2.46$ & $5,0 \pm 1,43$ \\
Defeitos Menores(\%) & $8,33 \pm 1,76$ & $7,50 \pm 2,60$ & $9,0 \pm 2,03$ & $10,0 \pm 2,06$
\end{tabular}

Tabela 9- Efeitos do tratamento de amostras espermáticas caprinas criopreservadas com diferentes concentrações de glutationa peroxidase $(0,1,5$ e $10 \mathrm{UI} / \mathrm{mL})$ nas taxas de espermatozóides com membrana e acrossomo íntegros, espermatozóides com atívidade mitocondrial DAB I, DAB II, DAB III e DAB IV, e susceptibilidade ao estresse oxidativo (TBARS). Poços de Caldas, MG

\begin{tabular}{lcccc} 
& Controle & GPX-1 & GPX-05 & GPX-10 \\
\cline { 2 - 5 } & & & & \\
\hline M. Plasmática(\%) & $25,08 \pm 4,80$ & $18,75 \pm 2,90$ & $20,58 \pm 2,02$ & $14,58 \pm 3,90$ \\
SCSA(\%) & $3,53 \pm 0,82$ & $3,10 \pm 0,35$ & $4,32 \pm 0,56$ & $3,74 \pm 0,86$ \\
Acrossomo(\%) & $45,33 \pm 6,75$ & $42,25 \pm 7,15$ & $43,92 \pm 6,83$ & $43,42 \pm 7,51$ \\
DAB I (\%) & $44,0 \pm 5,18$ & $35,25 \pm 4,91$ & $44,50 \pm 4,07$ & $39,58 \pm 6,92$ \\
DAB II(\%) & $26,33 \pm 2,99$ & $3,50 \pm 3,86$ & $27,58 \pm 4,51$ & $25,83 \pm 5,83$ \\
DAB III(\%) & $10,17 \pm 2,76$ & $12,25 \pm 2,20$ & $9,33 \pm 1,52$ & $11,33 \pm 2,89$ \\
DAB IV(\%) & $19,50 \pm 2,86$ & $21,0 \pm 4,37$ & $18,58 \pm 3,29$ & $23,25 \pm 3,68$ \\
TBARS (ng/10 & $625,67 \pm 169,54$ & $518,50 \pm 86,62$ & $665,72 \pm 170,12$ & $672,19 \pm 140,46$ \\
sptz) & & & & \\
\hline \hline
\end{tabular}




\begin{tabular}{|l|c|c|c|c|c|c|c|c|}
\hline & Memb. & SCSA & $\begin{array}{c}\text { TBARS } \\
\left(\mathrm{ng} / 10^{6}\right. \\
\text { sptz }\end{array}$ & ACRO & DAB I & DAB II & DAB III & DAB IV \\
\hline Memb. & 1.00 & 0.15 & -0.29 & 0.46 & -0.13 & -0.08 & -0.06 & 0.28 \\
& $(0.0)$ & $(0.56)$ & $(0.24)$ & $(0.06)$ & $(0.60)$ & $(0.76)$ & $(0.80)$ & $(0.26)$ \\
\hline SCSA & & 1.00 & 0.25 & -0.007 & -0.08 & 0.12 & 0.44 & -0.17 \\
\hline (nB/10 \\
sptz)
\end{tabular}

Figura 7- Correlação entre as taxas de espermatozóides com membrana e acrossomo íntegros, espermatozóides com atívidade mitocondrial DAB I, DAB II, DAB III e DAB IV, e susceptibilidade ao estresse oxidativo (TBARS) em sêmen criopreservado de caprinos suplementado com diferentes concentrações de glutationa peroxidase. Poços de Caldas, MG

Da mesma forma que o tratamento com catalase, o tratamento com glutationa peroxidase (GPx), também responsável pela destruição do peróxido de hidrogênio, baseava-se na maior susceptibilidade dos espermatozóides caprinos ao ataque desta espécie reativa de oxigênio verificada no Experimento 1. No entanto, não foram verificados efeitos do 
tratamento com GPx nas anormalidade morfológicas espermáticas ou mesmo na análise funcional do sêmen (Tabelas 9, 10 e 11). Sabe-se que um tratamento antioxidante só é eficiente em sistemas que esteja submetidos ao estresse oxidativo, que se caracteriza por um desbalanó entre uma maior produção de especies reativas de oxigênio e/ou uma menor produção de antioxidante (JONES; MANN, 1977; HALLIWELL, 1991).

De fato, um tratamento antioxidante pode também ser deletério ao espermatozóide, visto que as espécies reativas de oxigênio apresentam importante papel na fisiologia normal do espermatozóide (LAMIRANDE et al., 1997). 
$\underline{\text { Considerações finais }}$ 


\section{CONSIDERAÇÕES FINAIS}

Para amostras que apresentem estresse oxidativo, isto é, um desbalanço entre uma maior produção de ROS e uma menor atividade antioxidante, quantidades insuficientes de antioxidante em uma suplementação não apresentariam os efeitos desejados. Assim, o tratamento com diferentes concentrações de antioxidantes visando identificar a concentração ideal é imprescindível. A ausência de efeitos significativos do tratamento antioxidante, para algumas variáveis avaliadas no presente experimento, pode ter ocorrido pela suplementação com níveis insuficientes ou excessivos.

Outro aspecto a ser levado em consideração em uma terapia visando evitar os efeitos lesivos das ROS, seria o antioxidante a ser utilizado. A formação e destruição das ROS é uma reação em cadeia em que cada um dos antioxidantes, em seqüência, elimina as ROS formadas. Assim, caso o antioxidante utilizado no tratamento não seja o responsável pela destruição da ROS mais deletéria em um determinado momento, este tratamento não apresentará os efeitos desejados. Além disso, como visto anteriormente, na escolha do antioxidante utilizado, é importante avaliar seu local de ação. Os diferentes antioxidantes apresentam atuação mais destacada em determinados compartimentos específicos da célula. Assim, caso os danos causados pelo estresse oxidativo não envolverem este determinado compartimento, o tratamento antioxidante não será eficiente (NICHI, 2009).

Estudo anterior avaliando o efeito de diferentes antioxidantes no sêmen de bovinos coletado do epidídimo, indicam que diferentes antioxidantes atuam em locais diferentes, nos animais, o tratamento de amostras espermáticas com antioxidantes, como $\alpha$-tocoferol, ácido ascórbico (vitamina $C$ ) e algumas enzimas antioxidantes, também tem sido estudado com resultados diversos. O ácido ascórbico atua na proteção do citocromo P-450 contra a destruição por pseudo-substratos oxidativos e oxigênio (FRAGA et al., 1991). O $\alpha$-tocoferol atua na membrana plasmática, como um antioxidante lipo-solúvel, prevenindo a reação oxidativa em cadeia (MATÈS, 2000).

Por sua vez, os antioxidantes enzimáticos atuam em cascata, sendo que a superóxido dismutase provoca a dismutase do ânion superóxido $\left(\mathrm{O}_{2}^{-}\right)$, provocando a formação do peróxido de hidrogênio $\left(\mathrm{H}_{2} \mathrm{O}_{2}\right)$. Este, por sua vez, pode ser destruído pela catalase ou pela 
glutationa peroxidase (HALLIWELL; GUTTERIDGE, 1989), evitando a formação do radical hidroxila (OH-), a ROS mais prejudicial ao espermatozóide (HALLIWELL, 1991).

Podemos considerar que através de trabalhos realizados anteriormente, os antioxidantes podem agir de maneiras diferentes, considerando o local de atuação do antioxidante como também o compartimento mais susceptível ao estresse oxidativo. Nichi (2009), verificou que alguns teriam maior atividade em membrana e acrossomo e outros atuariam melhor no compartimento intracelular (i.e., mitocôndria, DNA). Dessa forma, combinando-se diferentes antioxidantes poderia melhorar a qualidade espermática de amostras submetidas ao estresse oxidativo, como por exemplo amostras criopreservadas.

Apesar dos resultados do experimento 1, indicarem que o peróxido de hidrogênio é a espécie reativa de oxigênio mais deletéria ao sêmen de caprinos, não houve efeito positivo dos antioxidantes responsáveis pela detruição desta ROS. No entanto, esta indução é realizada com níveis bastante altos de espécies reativas de oxigênio, o que poderia não representar o verdadeiro limiar dos espermatozóides caprinos na resistência ao estresse oxidativo que ocorreria durante à criopreservação. Assim, o tratamento com antioxidante poderia não ser eficiente nas quantidades utilizadas.

Importantes processos fisiológicos são dependentes de quantidades moderadas de espécies reativas de oxigênio, no qual o tratamento em doses excessivas pode ser deletério pois podem bloquear esses processos. Além disto, apesar do sêmen fresco ser mais susceptível ao estresse oxidativo, como verificado no experimento 1 , o sêmen criopreservado pode ser mais susceptivel a outra espécie reativa de oxigênio. De fato, resultados preliminares indicam uma diferença na susceptibilidade ao estresse oxidativo em sêmen fresco e criopreservado de caprinos, sendo o sêmen fresco mais susceptível ao peróxido de hidrogênio e o sêmen criopreservado mais suceptível ao radical hidroxila (SILVA et al., 2010). 
$\underline{\text { Referências }}$ 


\section{REFERÊNCIAS}

AITKEN, R. J. A Free radical theory of male infertility. Reproduction, Fertility and Development, v. 6, n.1, p. 19-24, 1994.

AITKEN, R. J. Sperm function tests and fertility. International Journal of Andrology, v. 29, p. 69-75, 2006.

ARUOMA, O. I.; HALLIWELL, B.; LAUGHTON, M. J.; QUINLAN, G. J.; GUTTERIDGE, J. M. The mechanism of initiation of lipid peroxidation. Evidence against a requirement for an iron(II)-iron(III) complex. The Biochemical Jornal, v. 258, n. 2, p. 617-620, 1989.

ARRUDA, R. P.; BARNABE, V. H.; ALENCAR, M. M.; BARNABE, R. C. Avaliação de sêmen congelado de bovinos. Provas lenta e rápida de termo-resistência: efeitos sobre a fertilidade. Brazilian Journal of Veterinary Research and Animal Science, v. 29, n. 1, p. 131-137, 1992.

ARRUDA, R. P.; BARNABE, V. H.; ALENCAR, M. M.; BARNABE, R. C. Teste de Termoresistência Rápido: Uma Opção para Avaliar a Fertilidade do Sêmen Congelado Bovino.

Revista Brasileira de Reprodução Animal, v. 01, p. 178-182, 1989.

ARRUDA, R. P.; CELEGHINI, E. C. C.; SOUZA, L. W. O.; NASCIMENTO, J.;

ANDRADE, A. F. C.; RAPHAEL, C. F.; GARCIA, A. R. Importância da qualidade do sêmen em programas de IATF e TETF. Acta Scientiae Veterinariae, v. 33, p. 145-150, 2005.

BALL, B. A.; GRAVANCE, C. G.; MEDINA, V.; BAUMBER, J.; LIU, I. K. Catalase activity in equine semen. Animal Jounal Veterinary Research. v. 61, n. 9, p. 1026 -1030, 2000 .

BARTH, A. D.; OKO, R. J. Abnormal morphology of bovine spermatozoa. Ames: Iowa State University Press, 1989. 285 p.

BARROS, P. M. H. Estresse oxidativo e integridade do DNA em sêmen resfriado de gatodo-mato (Leopardus tigrinus, SCHREBER,1775). 2007. 120 f. Tese (Doutor em Medicina Veterinária) - Faculdade de Medicina Veterinária e Zootecnia, Universidade de São Paulo, São Paulo, 2007. 
BEZERRA F. S. B. Inseminação artificial em caprino. Acta Veterinaria Brasilica, v. 4, p. S26-S29, 2010.

BILODEAU, J. F.; CHATTERJEE, S.; SIRAND, M. A.; GAGNON, C. Levels of antioxidant defenses are decreased in bovine spermatozoa after a cycle of freezing and thawing. Molecular Reproduction and Development, v. 55, p. 282-288, 2000.

BLAIR, I. A. DNA Adducts with Lipid Peroxidation Products. Journal of Biological Chemistry. v. 283, p. 15545-15549, 2008.

BLAIR, I. A. Lipid hydroperoxide-mediated DNA damage. Experimental Gerontology. v. 36, n. 9, p. 1473-1481, 2001.

BLUMER, C. G.; FARIELO, R. M.; RESTELLI, A. E.; SPAINE, D. M.; BERTOLLA, R. P.; CEDENHO, A. P. Serm nuclear DNA fragmentation and mitochondrial activity in men with varicocele. Fertility and Sterility, v. 90, n. 5, p. 1716-1722, 2008.

CABRERA, F.; GONZÁLEZ, F.; BATISTA, M.; CALERO, P.; MEDRANO, A.; GRACIA, A. The effect of removal of seminal plasma, egg yolk level and season on sperm freezability of canary buck (Capra hircus). Reproduction Domestic Animal. v. 40, n. 3, p. 191-195, 2005.

CÂMARA, D. R.; GUERRA, M. M. P. Mitocôndria espermática: além da síntese de adenosina trifosfato (ATP). Revista Brasileira de Reprodução Animal, v. 32, n. 2, p. 93-99, 2008.

CARDOSO, R.C.S.; SILVA, A.R.; SILVA, L.D.M. Use of the powdered coconut water (ACP®-106) for cyopreservation of canine spermatozoa. Animal Reproduction Science, v.2, p.257-262, 2005.

CUNNINGHAM, J. G.; KLEIN, B. G. Tratado de fisiologia veterinária. 4. ed. Rio de Janeiro: Elsevier, 2008, 710 p. 
EVENSON, D. P.; JOST, L. K.; MARSHALL, D.; ZINAMAN, M. J.; CLEGG, E.; PURVIS, K.; DE ANGELIS, P.; CLAUSSEN, O. P. Utility of the sperm chromatin structure assay as a diagnostic and prognostic tool in the human fertility clinic. Human Reproduction, v. 14, n. 4, p. 1039-1049, 1999.

FAO Food and Agriculture Organization, 2006. Disponível em: < http://www.fao.org $>$. Acesso em: 25 janeiro 2011.

FOOTE, R. H. Catalase content of rabbit, ram, bull and boar semen. Jounal Animal Science, v. 21, p. 966-968, 1962.

FOOTE, R.H.; HARE, E. High catalase content of rabbit semen appears to be inherited. Jounal Andrology. v. 21, n. 5, p. 664-668, 2000.

FONSECA, C. O.; FILHO, V. R. V.; FILHO, A. M.; ABREU, J. J. Manual para exame Andrológico e avaliação do sêmen animal. Belo horizonte: Colégio Brasileiro de Reprodução Animal; Ministério da Agricultura e do Abastecimento, 1997. CBRA № 021/1997.

FRAGA, G. G.; MOTCHNIK, P. A.; SHIGENAGA, M. K.; HELBROCK, J. H.; JACOB, R. A.; AMES, B. Ascorbic acid protects against endogenous oxidative DNA damage in human sperm. Proceedings of the National Academy of Sciences of the United States, v. 88, p. 11003-11006, 1991.

FRANDSON, R. D.; WILKE, W. L.; FAILS, A. D. Anatomia e Fisiologia dos Animais de Fazenda. 6. ed. Rio de Janeiro: Guanabara, 2005. 454 p.

GASCA, S.; PELLESTOR, F.; ASSOU, S.; LOUP. V.; ANAHORY, T.; DECHAUD, H. Identifying new human oocyte marker genes: a microarray approach. Reproductive Biomedicine Online, v. 14, n. 2, p. 175-183, 2007.

GONÇALVES, P. B. D.; FIGUEIREDO, J. R.; FREITAS, V. J. F. Biotécnicas aplicadas à reprodução animal. 2. ed. São Paulo: Roca, 2008. 395 p.

HAFEZ, B.; HAFEZ, E. S. E. Anatomia da reprodução masculina. In: HAFEZ, B.; HAFEZ, E. S. E. Reprodução animal. 7. ed. São Paulo: Manole, 2004. p. 03-12.

HAFEZ, E. S. E.; HAFEZ, B. Reprodução animal. 7. ed. Barueri, SP: Manole, 2004. 513 p. 
HAFEZ, E. S. E.; HAFEZ, B. Reproduction in farm animals. 7th ed. Philadelphia: Lippincot Williams \& Wilkins, 2000. 542 p.

HALLIWELL, B. Reactive oxygen species in living systems: source, biochemistry and role in human disease. American Journal of Medicine, v. 91, p. 14-22, 1991

HALLIWELL. B.; GUTTERIDGE, J. M. Free radicals in biology and medicine. Oxford: Claredon Press, 1989. p. 543.

HAMMERSTED, R. H.; GRAHAM, J. K.; NOLAN, J. P. Cryopreservation of mammalian sperm: What we ask them to survive. Journal of Andrology, v. 11, n. 1, p. 73-78, 1990.

HOLT, W. V. Basic aspects of frozen storage of semen. Animal Reproduction Science, v. 62 , p. 3-22, 2000.

HRUDKA, F. Cytochemical and ultracytochemical demonstration of cytochrome-c oxidase in spermatozoa and dynamics of changes accompanying ageing or induced by stress.

International Journal of Andrology, v. 10, n. 6, p. 809-828, 1987.

IBGE. Instituto Brasileiro de Geografia e Estatística. Indicadores IBGE - Estatística da produção pecuária, março 2009. Disponível em: <www.ibge.gov.br>. Acesso em: 23 abr. 2010.

JANERO, D. J. Malondialdehyde and thiobarbituric acid-reactivity indices of lipid peroxidation and peroxidative injury. Free Radical Biology \& Medicine, v. 9, p. 515-540, 1990.

JONES, R.; MANN, T. Damage to spermatozoa by peroxidation endogenous phospholipids. Journal of Reproduction and Fertility, v. 50, p. 261-268, 1977.

JONES, R.; MANN, T.; SHERINS, R. Peroxidative breakdown of phospholipids in human spermatozoa, spermicidal properties of fatty acids peroxides, and protective action of seminal plasma. Fertility and Sterility, v. 31, p. 531-537, 1979.

KUNDU, C. N.; CHAKRABARTY, J.; DUTTA, P.; BHATTACHARYYA, D.; GHOSH, A.; MAJUMDER G. C. Effect of dextrans on cryopreservation of goat cauda epididymal spermatozoa using a chemically defined medium. Reproduction. v. 123, p. 907-913, 2002. 
LAMIRANDE, E.; JIANG, H.; ZINI, A; KODAMA H.; GAGNON, C. Reactive oxygen species and sperm physiology. Reviews of Reproduction. v. 2, n. 1, p. 48-54, 1997.

MAIA, M. S.; BICUDO, S. D. Radicais livres, antioxidantes e função espermática em mamíferos: uma revisão. Revista Brasileira de Reprodução Animal, v. 33, n. 4, p. 183-193, 2009.

MATÉS, J. M. Effects of antioxidant enzymes in molecular control of reactive oxygen species toxicology. Toxicology, v. 153, n. 5, p. 83-104, 2000.

MCKINNON, A. O.; VOSS, J. L. Equine reproduction. 1. ed. North Providence Road: Williams \& Wilkins, p.1137, 1993.

NICHI, M. Efeito do tratamento com antioxidantes e ácidos graxos poli-insaturados em amostras espermáticas epididimárias de touros. 2009. 120 f. Tese (Doutor em Ciências) Faculdade de Medicina Veterinária e Zootecnia, Universidade de São Paulo, São Paulo, 2009.

NICHI, M. Sistemas de proteção enzimática e níveis de peroxidação espontânea dos lipídeos seminais de touros zebuínos e taurinos criados a campo na região de Dourados, MS. 2003, 101 f. Dissertação (Mestrado em Medicina Veterinária) - Faculdade de Medicina Veterinária e Zootecnia, Universidade de São Paulo, São Paulo, 2003.

NICHI, M.; BOLS, P. E. J.; ZÜGE, R. M.; BARNABE, V. H.; GOOVAERTS, I. G. F.; BARNABE, R. C.; CORTADA, C. N. M. Seasonal variation in semen quality in Bos indicus and Bos taurus bulls raised under tropical conditions. Theriogenology, v. 66, p. 822-828, 2006.

NORDBERG, J.; ARNÉR, E. S. J. Reactive oxygen species, antioxidants, and the mammalian thioredoxin system. Free Radical Biology \& Medicine, v. 31, n. 11, p. 1287-1312, 2001.

OHKAWA, H.; OHISH, N.; YAGI, K. Assay for lipid peroxides in animal tissues by thiobarbituric acid reaction. Analytical Biochemistry, v. 95, p. 351-358, 1979.

OLLERO, M.; POWERS, R. D.; ALVAREZ, J. G. Variation of docosahexaenoic acid content in subsets of human spermatozoa at different stages of maturation: implications for sperm lipoperoxidative damage. Molecular Reproduction Development, v. 55, n. 3, p. 326-334, 2000. 
PARKS, J. E.; HAMMERSTEDT, R. H. Development changes occurring in the lipids of ram epididymal spermatozoa plasma membrane. Biology of Reproduction, v. 32, n. 3, p. 653668, 1985.

PARKS, J. E.; LYNCH, D. V. Lipid composition and thermotrophic phase behaviour of boar, bull, stallion, and rooster sperm membranes. Cryobiology, v. 29, n. 2, p. 255-266, 1992.

PERIS, S. I.; BILODEAU, J. F.; DUFOUR, M.; BAILEY, J. Impact of cryopreservation and reactive oxygen species on DNA integrity, lipid peroxidation, and functional parameters in ram sperm. Molecular Reproduction and Development, v. 74, p. 878-892, 2007.

POPE, C. E.; ZHANG, Y. Z.; DRESSER, B. L. A simple staining method for evaluating acrosomal status of cat spermatozoa. Journal of Zoo and Wildlife Medicine, v. 22, n. 1, p. 87-95, 1991.

PURDY, P.H. A review on goat sperm cryopreservation. Small Ruminant Research, v. 63, n. 3, p. 215-225, 2006

RHEMREV, J. P. T.; VERMEIDEN, J. P. W.; HAENEN, G. R. M. M.; DE BRUIJNE, J. J.; REKERS-MOMBARG, L. T. M.; BAST, A. Progressively motile human spermatozoa are well protected against in vitro lipid peroxidation imposed by induced oxidative stress. Andrology, v. 33, p. 151-158, 2001.

RODRIGUES, M.P. Perfil oxidativo e avaliação funcional de sêmen cripreservado de touros (Bos taurus taurus e Bos taurus indicus) criados em clima tropical. 2009. $144 \mathrm{f}$. Dissertação (Mestre em Medicina Veterinária) - Faculdade de Medicina Veterinária e Zootecnia, Universidade de São Paulo, São Paulo, 2009.

SAKKAS, D.; ALVAREZ, J. G. Sperm DNA Fragmentation: mechanisms of origin, impact on reproductive outcome, and analysis. Fertility and Sterility, v. 93, n. 4, p. 1027-1036, 2010 .

SALAMON, S.; MAXWELL, W. M .C. Storage of ram semen. Animal Reproduction Science, v. 62, n. 1, p.77-111, 2000.

SENGOKU, K.; TAMATE, K.; YOSHIDA, T.; TAKAOKA, Y.; MIYAMOTO, T.; ISHIKAWA, M. Effects of low concentrations of nitric oxide on the zona pellucida binding ability of human spermatozoa. Fertility and Sterility, v. 69, n. 3, p. 522-527, 1998. 
SILVA, R. O. C.; NICHI, M.; PEREZ, E. G. A.; CABRAL, R. P.; VIANA, C. H. C.; TEODORO, A. C.; SILVA, D. G.; GÓES, P. A. A.; FERREIRA, G. H.; BARNABE, R. C.; BARNEBE, V. H. Susceptibility of goat sperm to different reactive oxygen species.

Reproduction, Fertility and Development, v. 22, n. 1, p. 316, 2010.

STRZEZEK, R.; KOZIOROWSKA-GILUN, M.; KOWALÓWKA, M.; STRZEZEK, J. Characteristics of antioxidant system in dog semen. Jounal Veterinary Science, v. 12, n. 1, p. 55-60, 2009.

TESARIK, J.; GRECO, E.; MENDOZA, C. Late, but not early, paternal effect on human embryo development is related to sperm DNA fragmentation. Human Reproduction. v. 19, p. 611-615, 2004.

TURNER, R. M. Moving to the beat: a review of mammaliam sperm motility regulation. Reproduction, Fertility and development, v. 18, p. 25-38, 2006.

WATSON, P. F. Recent developments and concepts in the cryopreservation of spermatozoa and the assessment of their post-thawing function. Reproduction, Fertility and Development, v. 7, p. 871-891, 1995.

WATSON, P. F. The causes of reduced fertility with cryopreserved semen. Animal Reproduction Science, v. 60-61, p. 481-492, 2000.

YOSHIDA, M. Conservation of sperms: current status and new trends. Animal Reproduction Science, v. 60-61, p. 349-355, 2000.

ZABLUDOVSKY, N.; ELTES, F.; GEVA, E.; BRKOVITZ, E.; AMIT, A.; BARAK, Y.; HAR-EVEN, D.; BARTOOV, B. Relationshit between human sperm lipid peroxidation, comprehensive quality parameter and IVF outcome. Andrology, v. 31, p. 91-98, 1999.

ZALATA, A. A.; CHRISTOPHE, A. B.; DEPUYDT, E.; SCHONJANS, F.; COMHAIRE, F. $H$. The fatty acid composition of phospholipids of spermatozoa from infertile patients.

Molecular Human Reproduction, v. 4, p. 111-118, 1998. 